\title{
Study on Removal Mechanism and Surface Quality of High Volume Fraction SiCp/Al Composites Based on Meso-Scale
}

Po Jin

Liaoning University of Technology

Qi Gao ( $\square$ qqonline@163.com )

Liaoning University of Technology

Quanzhao Wang

Institute of Metal Research Chinese Academy of Sciences

Wenbo Li

Liaoning University of Technology

\section{Research Article}

Keywords: SiCp/Al composites, Milling mechanism, Surface roughness

Posted Date: May 5th, 2021

DOl: https://doi.org/10.21203/rs.3.rs-461121/v1

License: (c) (i) This work is licensed under a Creative Commons Attribution 4.0 International License. Read Full License

Version of Record: A version of this preprint was published at Silicon on July 15th, 2021. See the published version at https://doi.org/10.1007/s12633-021-01262-6. 


\title{
Study on removal mechanism and surface quality of high volume fraction
}

\section{SiCp/Al composites based on meso-scale}

\author{
Po Jin ${ }^{1}$. Qi Gao'. Quanzhao Wang ${ }^{2}$. and Wenbo $\mathrm{Li}^{1}$ \\ ${ }^{1}$ School of Mechanical Engineering and Automation,Liaoning University of Technology, 121001 \\ ${ }^{2}$ Institute of Metal Research, Chinese Academy of Science, 110016 \\ Corresponding Author: Dr. Qi Gao \\ Email: qqonline@163.com
}

Abstract: The milling process of SiCp/Al composites with high volume fraction and large particle size has been studied in this paper. The stress and strain distribution of $\mathrm{SiC}$ reinforced particles and the removal mechanism of the material are analysed. The effects of milling depth and feed per tooth on surface quality were analysed. The effect of feed per tooth on the thickness of subsurface damage layer is revealed. The results show that in the end milling process of high volume fraction $\mathrm{SiCp} / \mathrm{Al}$ composites, the blade diameter is larger relative to the particle size, which leads to the main removal forms of particle size: extrusion crushing and rolling crushing. The surface defects of the machined workpiece mainly include cavity, crack and delamination caused by extrusion of aluminum matrix. The surface quality of the machined workpiece can be improved by increasing the milling depth appropriately. The increase of the feed rate of each tooth will lead to the increase of the surface defect of the machined workpiece and the deterioration of the surface quality. When the feed rate per tooth increases from 4 to $8 \mu \mathrm{m}$, the thickness of subsurface damage increases from 47.7 to $60.5 \mu \mathrm{m}$. It found that the ratio between the minimum cutting thickness of SiCp/Al composites and the radius of the cutting edge should be less than or equal to $4 \%$.

Key words: $\mathrm{SiCp} / \mathrm{Al}$ composites. Milling mechanism. Surface roughness

\section{1.introduction}

Silicon carbide particle aluminum matrix $(\mathrm{SiCp} / \mathrm{Al})$ composites have excellent comprehensive properties such as high specific strength, high specific modulus and high temperature resistance. They are mainly used in satellite bearings, aero-engines and inertial navigation systems. With the increasing demand for material properties in the fields of aerospace, automotive and optical precision instruments. SiCp/Al composites have attracted more and more attention due to their excellent properties.

As the urgent need of $\mathrm{SiCp} / \mathrm{Al}$ composites in various projects, the processing technology of $\mathrm{SiCp} / \mathrm{Al}$ composites has been widely concerned by scholars. Wang et al.[1] established the random distribution model of circular $\mathrm{SiC}$ particles and the random distribution model of polygon $\mathrm{SiC}$ particles with high volume fraction. The simulation results show that the main causes of defects are the rotation, pull-out, crushing, micro-fracture and cutting of $\mathrm{SiC}$. In the aspect of cutting force, the fluctuation of cutting force of polygon particle model is larger than that of circular particle model. Teng et al.[2] used Abaqus software to simulate the micromachining process considering the cutting edge radius, and established a two-dimensional finite element model of micromachining. The Von Mises stress and strain distribution in the workpiece under the influence of the interaction between the tool and the particle, chip formation process, cutting force and chip thickness were revealed. Niu et al.[3] conducted a processing experiment with polycrystalline diamond (PCD) tool on a high-precision miniature milling machine. The interaction between cutter and particle and the process of chip formation are analysed. The surface roughness, morphology, texture and defect of workpiece were analysed. And the optimum technological parameters are selected. Suresh Kumar Reddy et al. [4] studied the surface quality and subsurface damage degree of $\mathrm{SiCp} / \mathrm{Al}$ composites and aluminum alloys under different cutting conditions. By comparing the surface integrity (surface roughness, residual stress, microstructure and microhardness), the machinability of the two materials is understood. The research results are helpful to better 
understand the end milling process. Pramanik et al.[5] analysed the influence of feed rate on surface roughness, surface profile, surface morphology, chip surface, chip ratio, machining force and force signal. The results show that the machining speed has no obvious effect on the machining force at low feed rate, but the machining speed decreases with the increase of feed rate at high feed rate. Dabade et al.[6] studied two kinds of SiCp/Al $10 \%$ composites with different particle sizes (220 mesh and 600 mesh). The effect of hot working on the machinability and surface quality of $\mathrm{SiCp} / \mathrm{Al}$ composites was studied. The results show that $\mathrm{Al} / \mathrm{SiC} / 10 \mathrm{P} / 220$ and $\mathrm{Al} / \mathrm{SiC} / 10 \mathrm{P} / 600$ composites have good surface roughness at $60^{\circ} \mathrm{C}$. Ghoreishi et al.[7] studied the effect of different cutting parameters on tool wear of low volume fraction $\mathrm{SiCp} / \mathrm{Al}$ composites during low temperature and high speed cutting. It is found that low temperature cooling can reduce tool wear. Liu et al.[8] established an analytical model of micro-milling force prediction considering the effect of matrix size. The effects of milling width, milling depth and feed per tooth on milling force were studied. The results show that the milling force increases with the increase of three parameters. Deng et al.[9] proposed a two-body/three-body abrasive wear analysis method combined with adhesive wear to estimate the tool surface wear during micro-end milling of $\mathrm{SiCp} / \mathrm{Al}$ composites. It is found that the early wear is mainly adhesive wear, and the late wear is mainly two-body abrasive wear. Tool surface wear accounts for about $60 \%$ of tool wear.

In addition, the effects of particles and machining parameters on the wear process of the cutter face are analysed. Wang et al.[10] simulated the high speed milling process of high volume fraction SiCp/Al6063 composite by using multiphase two-dimensional finite element model and uniform equivalent material model. Through comparison, it is found that the multiphase model is helpful to discover the interaction between matrix, particle and tool, and more helpful to discover the complex stress distribution, and further understand the removal mechanism of $\mathrm{SiCp} / \mathrm{Al} 6063$ composite. Wang et al.[11] studied the performance of polycrystalline diamond (PCD) tool for high speed milling of large volume fraction $\mathrm{SiC}$ particle reinforced aluminum. The results show that the tool wear increases obviously with the increase of milling speed. Bian et al.[12] conducted precision milling research on $\mathrm{SiCp} / \mathrm{Al}$ composites with high volume fraction and large granularity. The cutting mechanism and wear characteristics of $\mathrm{SiCp} / \mathrm{Al}$ composites are revealed. In order to improve the micromachining properties of 65 vol\% $\mathrm{SiCp} / \mathrm{Al}$ composites. Zhao et al.[13] proposed a new method of laser induced oxidation assisted micromilling. The milling mechanism of $\mathrm{SiCp} / \mathrm{Al}$ composites was studied. Through comparison, the practicability and high efficiency of the proposed mixing process are verified. Gavalda Diaz et al.[14] studied the surface quality and subsurface damage of $\mathrm{SiCp} / \mathrm{Al}$ composites machined under different cutting conditions. Quan et al.[15] studied the hardness and residual stress of $\mathrm{SiCp} / \mathrm{Al}$ composites during processing. The results show that the residual stress on the surface of coarse-grained reinforced composites may be released due to structural defects. However, the residual stress on the surface of the composite reinforced by fine grains tends to compress. Teng et al.[16] used the finite element method to compare the cutting mechanism of $\mathrm{SiCp} / \mathrm{Al}$ metal matrix composites reinforced by micro and nano particles. It is found that the nano particles remain intact in the cutting process and are easy to produce continuous chips, while the micro particles are easy to break and form intermittent chips. Compared with microsized composites, nano-reinforced composites have better surface quality and fewer defects. Setia et al.[17] established two kinds of finite element cutting simulation models with uniform and serrated reinforced particles as the research objects. By comparing the two different types of finite element simulation, the output cutting force and cutting temperature in the machining process are predicted. Lu et al.[18] studied the influence of cutting path on the ultra-precision multi-step cutting performance of low volume fraction $\mathrm{SiCp} / \mathrm{Al}$ composites by combining finite element simulation and experimental characterization. It is found that the cutting order has a significant effect on the particle-tool interaction and machining surface quality. This provides guidance for improving the surface finish of $\mathrm{SiCp} / \mathrm{Al}$ composites. Li et al.[19-20] compared ultrasonic processing with 
traditional processing. It is found that the ultrasonic amplitude has a great influence on the surface roughness of $\mathrm{SiCp} / \mathrm{Al}$ material, which is next to the cutting speed, followed by the tooth feed and cutting depth. The surface quality of $\mathrm{SiCp} / \mathrm{Al}$ materials can be improved by using ultrasonic machining technology. Wang et al.[21] established an optimal surface roughness prediction model based on multiple linear regression equations, designed an orthogonal experimental array, and studied the effects of different parameters on the surface roughness of materials. Using response surface method. Ali Laghari et al.[22] established a second-order model of cutting force under different cutting parameters such as cutting speed, feed rate and cutting depth. The influence of actual machining conditions on the cutting force of $\mathrm{SiCp} / \mathrm{Al}$ composites in the turning process is analysed.

In the past decades, a lot of experiments have been carried out on the cutting mechanism of $\mathrm{SiCp} / \mathrm{Al}$ composites. Most studies have focused on low volume fraction $\mathrm{SiCp} / \mathrm{Al}$ composites $(<30 \mathrm{Vol} \%)$.Compared with low volume fraction $\mathrm{SiCp} / \mathrm{Al}$ composites, the tool wear of high volume fraction $\mathrm{SiCp} / \mathrm{Al}$ composites in the machining process is more severe and the surface quality is more difficult to control [23-24]. In this paper, the milling process of high volume fraction $\mathrm{SiCp} / \mathrm{Al}$ composites is studied by combining finite element simulation and experiment. The influence of milling depth and feed per tooth on the surface quality of $\mathrm{SiCp} / \mathrm{Al}$ composites is revealed, which will promote the industrial application of this material.

\section{Simulation analysis based on particle random distribution model}

\subsection{Establishment of particle random distribution model}

The finite element simulation model of $\mathrm{SiC}$ aluminum matrix composites with random distribution of particles of different sizes was established. In order to observe the particle removal mechanism in the cutting process more clearly, the 3D micro-milling model was simplified into a two-dimensional orthogonal simulation experiment. The volume ratio of the composite material is $60 \%$, the particle diameter is mainly $20 \mu \mathrm{m}$ and $60 \mu \mathrm{m}$
$\mathrm{SiC}$ particles mixed, the average particle size is about 40 $\mu \mathrm{m}$, the matrix material is A12024. In the simulation, it is assumed that the particle shape is round and the particles are distributed randomly in the matrix without overlap. The particle radius is randomly distributed within 10-30 $\mu \mathrm{m}$, and the particle random distribution and the milling model principle are shown in Fig. 1.

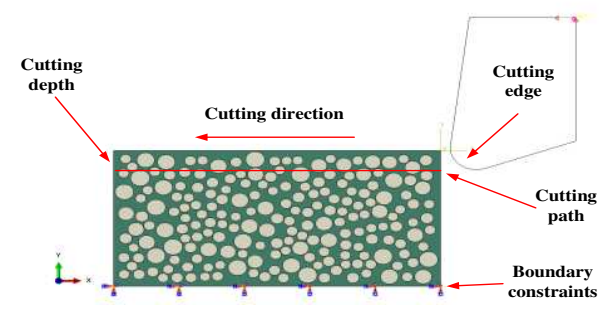

Fig. 1 Schematic diagram of the milling model

This model and simulation were carried out in the Abaqus software, and the dimensions used were length $(\mathrm{mm})$, mass ( $\mathrm{t})$ and time (s). The free mesh is used in the simulation, and the global mesh density of the $\mathrm{SiCp} / \mathrm{Al}$ composite model is $0.005 \mathrm{~mm}$. The grid unit adopts CPE4RT. The Dynamic, Temp-Disp and Explicit Step analysis steps are used in this simulation. The meshing are shown in Fig. 2

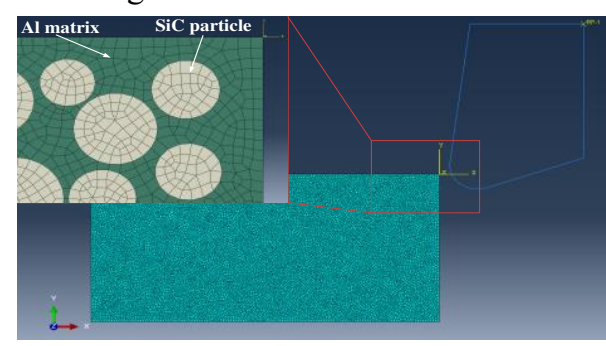

Fig. 2 Mesh division in the simulation model

\subsection{Material characteristics and failure criteria}

The matrix of the composite is Al2024, and the reinforcement is $\mathrm{SiC}$ particles. The elastic phase of the material is mainly determined by the elastic modulus and Poisson's ratio. The parameters are shown in Table 1.

\begin{tabular}{ccc} 
Table 1 Material parameters of A12024 and $\mathrm{SiC}$ & \\
\hline Material & Matrix: Al2024 & Particles: $\mathrm{SiC}$ \\
\hline Density $\left(\mathrm{g} / \mathrm{cm}^{3}\right)$ & 2.77 & 3.13 \\
Elastic modulus $(\mathrm{GPa})$ & 73 & 427.5 \\
Poisson's ratio & 0.33 & 0.14 \\
Thermal conductivity & 190 & 81 \\
Specific heat $(\mathrm{J} /(\mathrm{kgK}))$ & 875 & 427 \\
\hline
\end{tabular}

Aluminium is a typical plastic material. The Johnson cook (J-C) model is used to characterize its plastic deformation stage, and it is often characterized as follows: 


$$
\sigma=\left(A+B \bar{\varepsilon}^{p n}\right)\left(1+C \ln \frac{\dot{\bar{\varepsilon}}^{p n}}{\dot{\bar{\varepsilon}}_{0}}\right)\left[1-\left(\frac{T-T_{0}}{T_{\text {melt }}-T_{0}}\right)^{m}\right]
$$

where $\sigma$ is the flow stress (MPa); $\varepsilon$ is the effective plastic strain; $\dot{\varepsilon}$ is the effective plastic strain rate; $\dot{\varepsilon}_{0}$ is the reference plastic strain rate; $T$ is the environment temperature $\left({ }^{\circ} \mathrm{C}\right) ; T_{\mathrm{m}}$ is the melting point temperature of the material; $A$ is the yield stress of the material (MPa); $B$ is the work hardening parameters of the material $(\mathrm{MPa}) ; C$ is the strain rate enhancement index; $m$ is the temperature change rate index; and $n$ is the strain hardening index.

The Johnson-Cook fracture criterion and damage parameter $D$ were used to judge the material removal. $D$ was set to be 1 , and the unit was separated and removed. The expression is

$$
D=\sum \frac{\Delta \varepsilon}{\varepsilon^{f}}
$$

where $\varepsilon^{f}$ is the failure strain and $\Delta \varepsilon$ is the effective plastic strain increment under an increase in the load unit.

Using the J-C fracture criterion, the calculation formula for equivalent plastic strain is

$$
\varepsilon^{f}=\left[d_{1}+d_{2} \exp \left(\mathrm{d}_{3} \frac{\delta_{m}}{\bar{\delta}}\right)\right]\left(1+d_{4} \ln \frac{\dot{\varepsilon}}{\dot{\varepsilon}_{0}}\right)\left[1+d_{5}\left(\frac{T-T_{\mathrm{r}}}{T_{\mathrm{m}}-T_{\mathrm{r}}}\right)\right]
$$

where $\varepsilon^{f}$ is the equivalent plastic strain; $\delta_{m}$ is the average value of positive pressure $(\mathrm{MPa}) ; \delta$ is the effective stress (MPa); and $d_{1}-d_{5}$ are the material failure parameters. Table 2 shows the J-C model and J-C fracture model parameters of the 2024 aluminium alloy.

\begin{tabular}{cc} 
Table 2 Some parameters of matrix J-C model and J-C fracture model \\
\hline$A(\mathrm{MPa})$ & 369 \\
\hline$B(\mathrm{MPa})$ & 684 \\
$C$ & 0.0083 \\
$n$ & 1.7 \\
$d_{1}$ & 0.73 \\
$d_{2}$ & 0.112 \\
$d_{3}$ & 0.123 \\
$d_{4}$ & 1.5 \\
$d_{5}$ & 0.007 \\
$T_{\mathrm{m}}\left({ }^{\circ} \mathrm{C}\right)$ & 0 \\
$T_{\mathrm{r}}\left({ }^{\circ} \mathrm{C}\right)$ & 502 \\
\hline
\end{tabular}

The PCD tool is set as an analytical rigid body in the simulation. The cutting-edge radius is $10 \mu \mathrm{m}$, the rake angle is $7^{\circ}$ and the relief angle is $20^{\circ}$. The contact mode is face-to-face contact, and the Coulomb friction model is adopted, with a friction coefficient of 0.35 . The bottom of the matrix and the upper right part of the tool are constrained by the boundary.

\subsection{Criteria for chip separation}

The characteristics of the aluminium matrix also adopt the J-C and J-C fracture models, adopt brittleness removal criteria for $\mathrm{SiC}$ particles, and select a tensile stress standard to judge, and its characterization is as follows:

$$
\max \left(\delta_{1}, \delta_{2}, \delta_{3}\right)=\delta_{0}
$$

where $\delta_{1}, \delta_{2}, \delta_{3}$ is the principal stress $(\mathrm{MPa})$ and $\delta_{0}$ is the crushing stress of the $\mathrm{SiC}$ material (MPa).

In the failure criterion of brittle materials, the standard model of energy is used to measure the cracking and crack expansion of silicon carbide. The crack displacement during failure can be expressed by

$$
u_{n 0}=2 G_{f}^{l} / \delta_{m}^{l}
$$

where $u_{\mathrm{n} 0}$ is the nominal displacement $(\mu \mathrm{m}) ; G_{f}^{I}$ is the mode I fracture energy $\left(\mathrm{J} / \mathrm{m}^{2}\right)$; and $\delta_{m}^{I}$ is the critical stress of the mode I fracture (MPa).

The stress retention model is used to describe crack propagation due to shear stress. The shear modulus $G_{\mathrm{c}}$ after cracking can be calculated by the following formula:

$$
G_{c}=\left(1-\frac{e_{n n}^{c k}}{e_{\max }^{c k}}\right)^{p} G
$$

where $p$ and $e_{\max }^{c k}$ are material parameters; $G$ is the shear modulus of the material (MPa); and $e_{n n}^{c k}$ is the crack propagation strain. The brittle fracture parameters of the SiC material standards are shown in Table 3.

Table 3 Parameters of material brittleness removal

\begin{tabular}{cccc}
\hline$\delta_{0}$ & $G_{f}^{l}$ & $p$ & $e_{\max }^{c k}$ \\
\hline 1500 & 30 & 1 & 0.001 \\
\hline
\end{tabular}

\subsection{The relationship between the experiment and simulation}

In the experiment, the maximum milling depth is $50 \mu \mathrm{m}$, which is very small compared to the cutter diameter of $1000 \mu \mathrm{m}$, as shown in Fig. 3. In this case, the effect of the helix angle on chip formation and cutting force is negligible. Therefore, the machining process of $3 \mathrm{D}$ micro-milling is simplified to a $2 \mathrm{D}$ micro-orthogonal machining process. It is assumed that the uncut chip thickness in the cutting process is the same as that set in the simulation. 


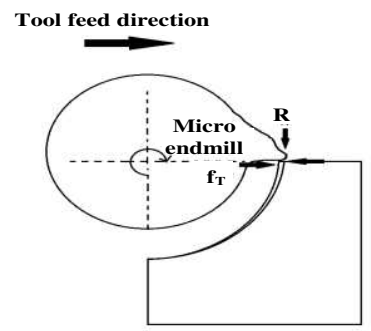

(a)

(b)

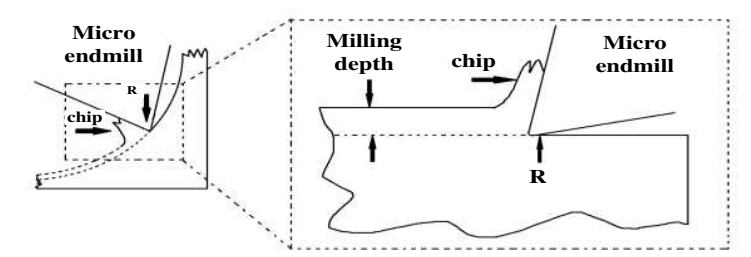

Fig. 3 (a) Two-dimensional milling process diagram when the tool rotates $180^{\circ}$; (b) Relationship between $2 \mathrm{D}$ milling process and orthogonal machining process.

\section{Analysis of cutting mechanism and results}

\subsection{Study on particle removal mechanism and influence of surface defect formation}

In the simulation, the cutting speed is set as 2198 $\mathrm{mm} / \mathrm{s}$, which is equivalent to the spindle speed of 14000

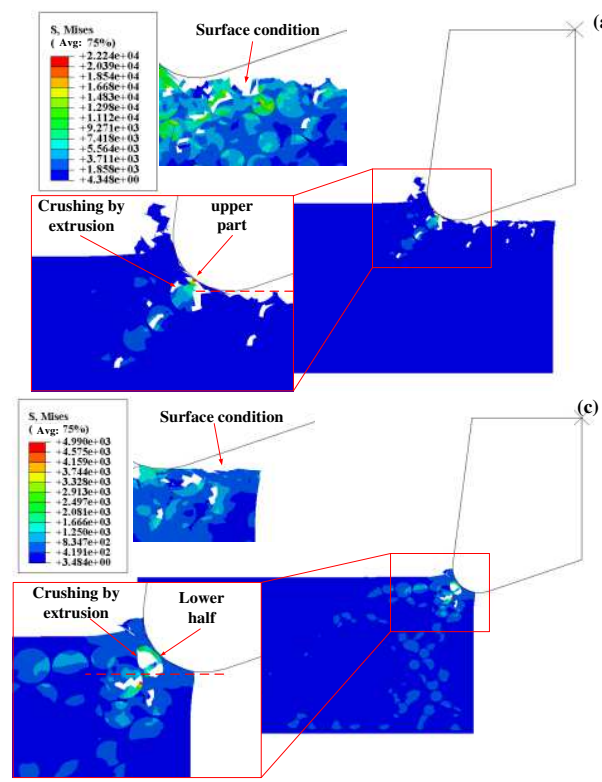

Fig. 4 Particle removal mode and stress distribution

It can be seen from Fig. 4 that the removal of particles is different when the cutter milling particles at different positions.In Fig. 4 (a), a cutter cutting the upper part of a particle is shown. The interface between the particle and the aluminum matrix is destroyed, and the aluminum matrix is plastic deformed when the cutter cuts the aluminum matrix first. The cutter continues to move forward to milling the particles, resulting in brittle deformation of the particles. As the cutting progresses, the particles are completely crushed and fall off, forming pits on the workpiece surface.

Fig. 4 (b) shows the situation near the middle position of the cutter cutting particles.Under the cutting tool, the interface between the particle and the aluminum matrix $\mathrm{r} / \mathrm{min}$, and the cutting thickness is $45 \mathrm{um}$. After the simulation, the removal of particles and surface defects were analysed, and it was found that the removal forms of composite materials were different at different locations of milling particles, as shown in Fig. 4.

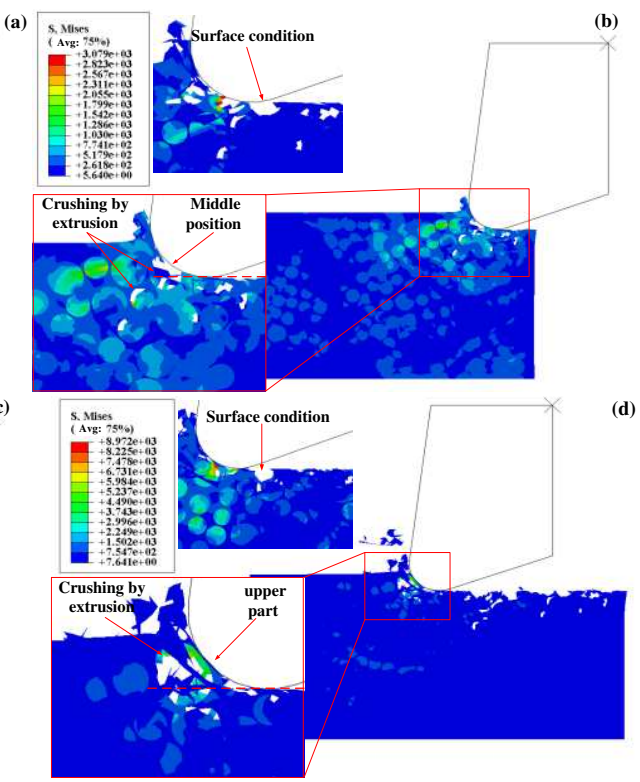

completely fails. The brittle deformation of the particles is removed and most of the particles are peeled off.The remaining part of the particle is expelled through the extrusion of the tool, forming pits on the workpiece surface.

In Fig. 4 (c) and (d), PCD tools are shown cutting the bottom and lower half of particles. When the tool is cutting the bottom of the particle, the contact surface near the particle and the matrix results in the complete failure of the constraint. With the progress of cutting, the particles are completely peeled off and the surface defects are small. When the tool cuts the lower half of the particle, the cutting edge contact with the particle causes the constraint to gradually lose effectiveness, and 
the lower half of the particle is crushed. Most of the particles are crushed to form small pits on the processed surface. At the same time, in the process of cutting particles are squeezed each other, will also make the particles broken and removed.

To sum up, in the milling process of high volume fraction $\mathrm{SiC}$ based composites, the main particle removal form is crushing. Most of the defects formed on the workpiece surface after the particles are removed are pits, which are caused by the larger diameter of the tool blade relative to the particles.

\subsection{Study on the influence of cutting thickness on particle removal and surface defect formation}

When the cutting speed is constant and the cutting thickness is different, the surface morphology and stress distribution of the machined workpiece are shown in Fig. 5

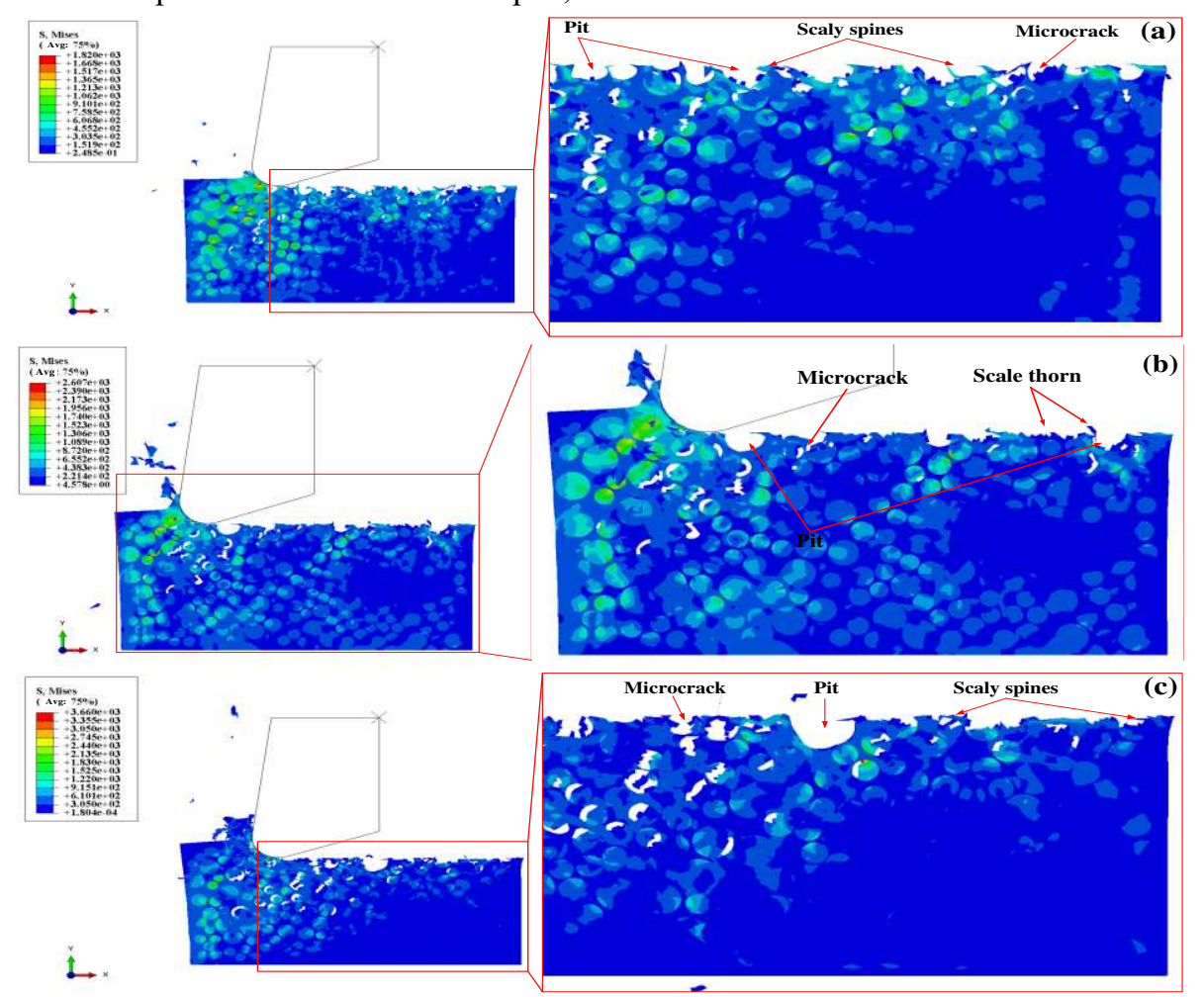

Fig. 5 Microstructure and stress distribution of workpiece surface (a) $\mathrm{N}=18000 \mathrm{r} / \mathrm{min}, V_{c}=2826 \mathrm{~mm} / \mathrm{s}, h=25 \mu \mathrm{m}$,; (b) $N=18000 \mathrm{r} / \mathrm{min}, V_{c}=2826 \mathrm{~mm} / \mathrm{s}$, $h=45 \mu \mathrm{m}$; (c) $N=18000 \mathrm{r} / \mathrm{min}, V_{c}=2826 \mathrm{~mm} / \mathrm{s}, h=65 \mu \mathrm{m}$

It can be seen from Fig. 5 that in the cutting process, the irregular stress distribution and stress concentration area are mainly the contact area between the tool and the particle. It can be concluded that stress concentration and irregular stress distribution are the main reasons for particle breakage, peeling, extrusion and surface defects. After the particles are peeled off, the surface of the workpiece appears many pits, some $\mathrm{SiC}$ particles are pressed by the cutting tool, such as aluminum alloy matrix, some broken particles remain in the pits, the particle cracks are uneven, the surface deformation is serious.

When the cutting thickness increases from $25 \mu \mathrm{m}$ to $65 \mu \mathrm{m}$, the surface pits become larger, the number of surface burrs decreases, and the width and depth of cracks increase.This is because the matrix size effect decreases when the cutting thickness increases from 25 $\mu \mathrm{m}$ to $65 \mu \mathrm{m}$. The increase of cutting thickness causes the particles to extrude each other, the depth of crack propagation increases, the amount of deformation continues to expand, and the surface of the workpiece cracks and pits.In addition, the volume of particles being cut increases, which leads to the increase of cutting force and the deterioration of surface quality.

With constant cutting speed and different cutting thickness, the equivalent plastic strain distribution is shown in Fig. 5. 

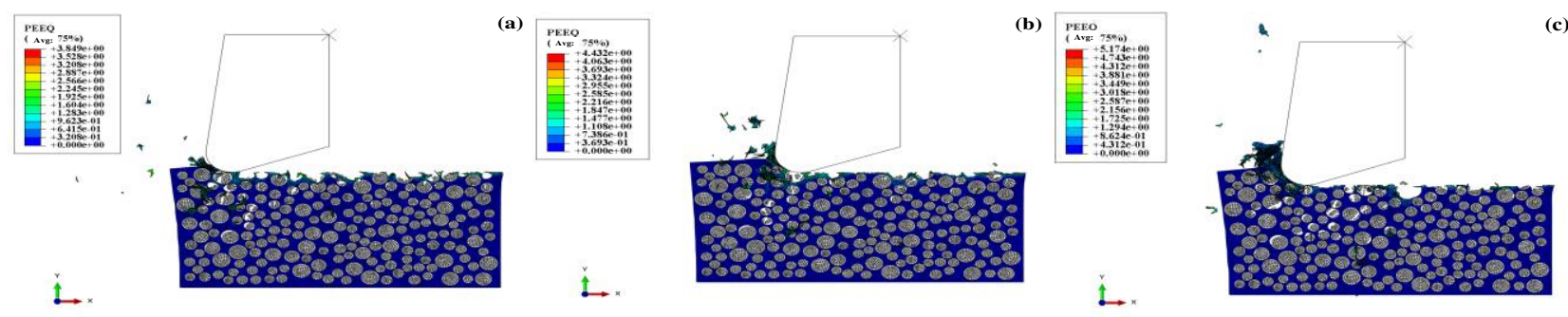

Fig. 6 Equivalent plastic strain distribution (a) $N=18000 \mathrm{r} / \mathrm{min}, V_{c}=2826 \mathrm{~mm} / \mathrm{s}, h=25 \mu \mathrm{m}$; (b) $N=18000 \mathrm{r} / \mathrm{min}, V_{c}=2826 \mathrm{~mm} / \mathrm{s}, h=45 \mu \mathrm{m}$; (c) $N=18000$ $\mathrm{r} / \mathrm{min}, V_{c}=2826 \mathrm{~mm} / \mathrm{s}, h=65 \mu \mathrm{m}$

There are three main deformation zones during cutting. The plastic deformation zone generated in the cutting layer near the cutting edge is the first deformation zone, the second deformation zone generated in the cutting surface contact with the front cutter surface, and the third deformation zone generated in the contact with the processed surface.

It can be seen from Fig. 5 that the maximum cutting stress is mainly distributed in the first variation zone near the cutting edge. The equivalent plastic strain distribution is shown in Fig. 6, and the maximum strain is mainly distributed in the first deformation zone. At the same cutting position, when the cutting thickness increases from $25 \mu \mathrm{m}$ to $65 \mu \mathrm{m}$, the equivalent plastic strain increases from 3.849 to 5.174 , and the strain value increases with the increase of cutting thickness. The processing method of $\mathrm{SiC}$ particles in $\mathrm{SiCp} / \mathrm{Al}$ composites is changed from negative front Angle extrusion to positive front Angle shear removal. With the increase of cutting thickness, the displacement of Al-SiC boundary towards $\mathrm{Al}$ matrix is intensified, the brittle fracture region of $\mathrm{SiC}$ particles becomes larger, and deeper holes and more subsurface damage are formed on

\section{Experimental scheme}

The experiment mainly studies and analyses the surface defects formed by a PCD end mill milling a groove when processing particle reinforced aluminium matrix composite $\mathrm{SiCp} / \mathrm{Al}$ and the influence of milling dosage on the surface quality. The material used in the experiment was a $\mathrm{SiCp} / \mathrm{Al}$ composite material composed of Al2024 aluminium alloy and $\mathrm{SiC}$ particles. The volume fraction of particles is $60 \%$. The particle part is mainly composed of $20 \mu \mathrm{m}$ and $60 \mu \mathrm{m}$ particles with an average size of $40 \mu \mathrm{m}$. A diamond end mill is selected as the experimental tool. The tool diameter is $1 \mathrm{~mm}$, the edge radius is $10 \mu \mathrm{m}$, the rake angle is $7^{\circ}$ and the relief angle is $20^{\circ}$.

This experiment was carried out on the 3D micro-milling machine platform as shown in Fig. 7, The surface roughness value of the material cuttings was measured by a real colour scanning microscope. The surface micromorphology of the material cuttings was observed by a Zeiss SIGMA 500 field emission scanning electron microscope, and the experimental equipment is shown in Fig. 8. the machined surface.

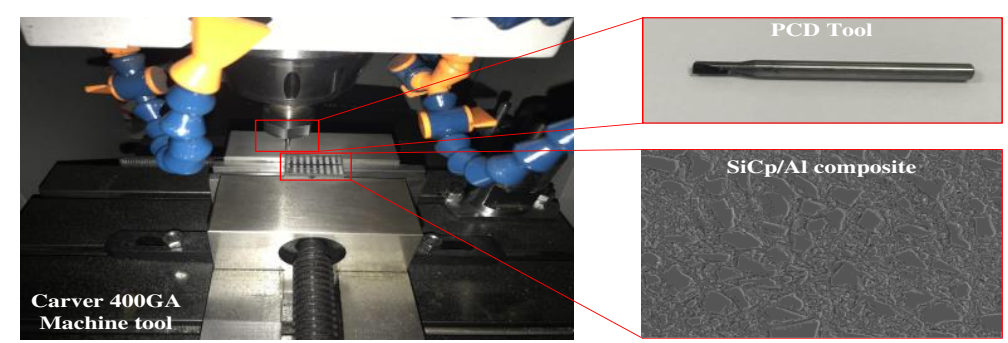

Fig. 7 Experimental site 

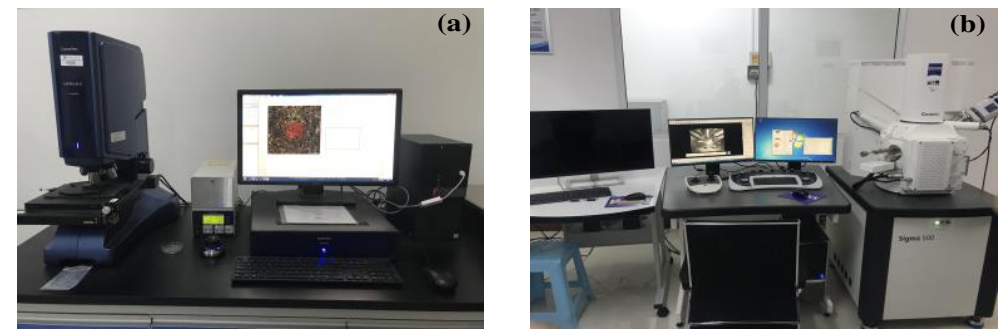

Fig. 8 Detection equipment (a) true color confocal microscope; (b)Zeiss Sigma 500 field emission scanning electron microscope

In the single factor milling test, the processing parameters used are shown in Table 4 below.

Table 4. Values of single factor experimental process parameters

\begin{tabular}{cc}
\hline Process parameters & Numerical value \\
\hline Spindle speed $(\mathrm{r} / \mathrm{min})$ & 18000 \\
Feed rate $(\mathrm{m} / \mathrm{min})$ & $0.072,0.108,0.144$ \\
Milling depth $(\mu \mathrm{m})$ & $25,45,65$ \\
\hline
\end{tabular}

\subsection{Influence of milling depth on particle removal and surface defect formation}

The micro-morphology of the machined surface of the workpiece was detected by using a true color confocal microscope. When the spindle speed and feed rate remain unchanged and different milling depths are used, the three-dimensional morphology characteristics of the machined surface of the workpiece are shown in Fig. 9.

\section{Analysis of experimental results}

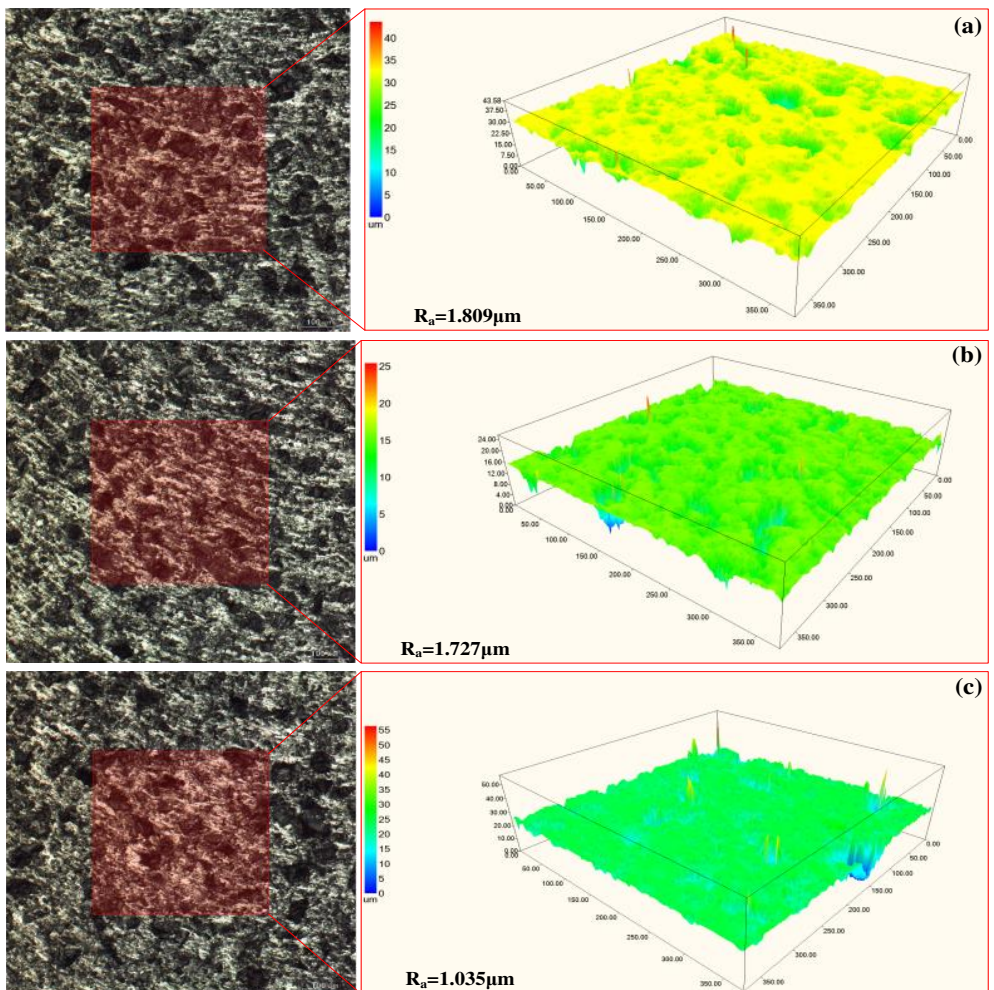

Fig. 9 Machined surface topography of $\mathrm{SiCp} / 2024 \mathrm{Al}$ composites (a) $N=18000 \mathrm{r} / \mathrm{min}, V_{f}=0.072 \mathrm{~m} / \mathrm{min}, a_{p}=25 \mu \mathrm{m}$; (b) $N=18000 \mathrm{r} / \mathrm{min}, V_{c}=0.072$ $\mathrm{m} / \mathrm{min}, a_{p}=45 \mu \mathrm{m}$; (c) $N=18000 \mathrm{r} / \mathrm{min}, V_{f}=0.072 \mathrm{~m} / \mathrm{min}, a_{p}=65 \mu \mathrm{m}$;

When the spindle speed and feed rate are constant and the milling depth is different, the changing trend of surface roughness is shown in Fig. 10.

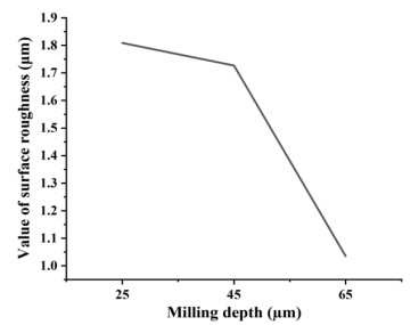


Fig. 10 Surface roughness variation trend

It can be seen from Fig. 9 that when the milling depth increases from 25 to $45 \mu \mathrm{m}$, the surface defects are reduced, and the surface small holes, pits and cracks are reduced. The size and depth of the surface roughness decrease with the increase of milling depth, and the surface roughness decreases from $1.809 \mu \mathrm{m}$ to $1.727 \mu \mathrm{m}$. When the milling depth is increased from $45 \mu \mathrm{m}$ to 65 $\mu \mathrm{m}$, the surface defects are further reduced, and there are few pits on the surface. The main defects are small holes and cracks, and their size and depth decrease with the increase of milling depth. However, the burr around the removed particles increased and the surface roughness decreased by $1.035 \mu \mathrm{m}$ from $1.727 \mu \mathrm{m}$. This shows that the defect which has the greatest influence on the surface roughness is pit.

Field emission scanning electron microscopy (SEM) was used to detect the microstructure of the material surface. The spindle speed was $18000 \mathrm{r} / \mathrm{min}$ and the feed rate was $0.072 \mathrm{~m} / \mathrm{mim}\left(f_{z}=4 \mu \mathrm{m}\right)$. When the milling depth was different, the surface defects of the processed material were shown in Fig. 11.
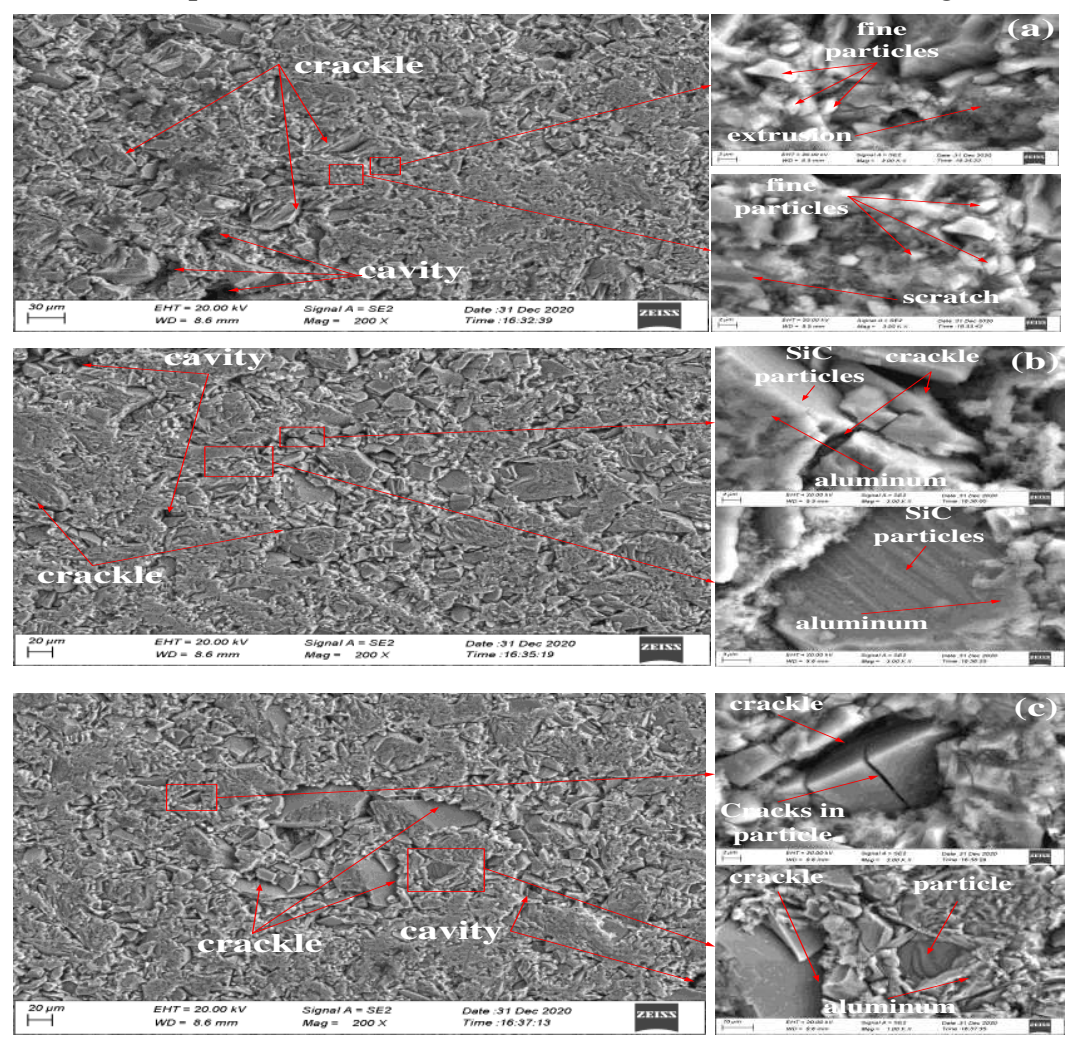

Fig. 11 Surface defect detection of machined materials (a) $N=18000 \mathrm{r} / \mathrm{min} 、 V_{f}=0.072 \mathrm{~m} / \mathrm{min} 、 a_{p}=25 \mu \mathrm{m} ;$ (b) $N=18000 \mathrm{r} / \mathrm{min} 、 V_{f}=0.072 \mathrm{~m} / \mathrm{min} 、 a_{p}=45$ $\mu \mathrm{m}$; (c) $N=18000 \mathrm{r} / \mathrm{min} 、 V_{f}=0.072 \mathrm{~m} / \mathrm{min} 、 a_{p}=65 \mu \mathrm{m}$;

Fig. 11 clearly shows the cracks and caviaries caused by the extrusion and crushing of particles in the milling process of composite materials, the scratches caused by the crushing of particles by cutting tools on the material surface, and the caviaries caused by the extrusion and discharge of particles, etc. As the milling depth increases, the number of small holes, pits and cracks on the workpiece surface decreases.

With the increase of milling depth, its size and depth decrease obviously, the surface scratches weaken obviously, and the surface consistency is enhanced. As can be seen from Fig. 10, when the milling depth increases from 25 to $45 \mu \mathrm{m}$, the surface roughness decreases slowly. When the milling depth increases from 45 to $65 \mu \mathrm{m}$, the surface roughness decreases sharply. A large number of small cracks and pits can be observed from Fig. 11(a). Part of the reason is the cracking phenomenon of the cover layer due to the extrusion of the aluminum matrix. Another part of the reason is that the milling particles are broken and peeled off to produce cracks and pits. By observing Fig. 11(b) and (c), it is found that with the increase of milling depth, the material cracks and pits gradually decrease, and the scratches left by $\mathrm{SiC}$ particles on the matrix surface also 
begin to decrease.

At this time, the feed rate per tooth is $4 \mu \mathrm{m}$, which is less than the minimum cutting thickness of aluminum matrix. The size effect is significant when the matrix is removed, and the coating effect is strong. But the material contained in the particle is large, and the silicon carbide particle is brittle material, when the cutter milling particle position upper, the particle will be completely broken, so when the milling depth is small, the cutting tool of particle crushing, extrusion effect is more obvious. The crushed particles fall off and produce more pits. In addition, the broken particles move with the milling cutter, scratch the surface of the workpiece, and promote the further increase of surface defects. When the milling depth is between 45 and $65 \mu \mathrm{m}$, the milling position of the particles is mostly the lower part, the crushed particles are mostly completely separated from the pits, the surface defects are reduced, and the surface consistency is enhanced. The heat generated in the milling process will also increase, and the residual heat will cause the softening of the aluminum matrix and make it wrap on the surface of the particles, thus improving the processing quality.

\subsection{Study on the influence of feed rate per tooth on particle removal and surface defect formation}

The spindle speed and milling depth remain unchanged. When different feed rate of each tooth are selected, the three-dimensional morphology characteristics of the machined surface of the workpiece are shown in Fig. 12.

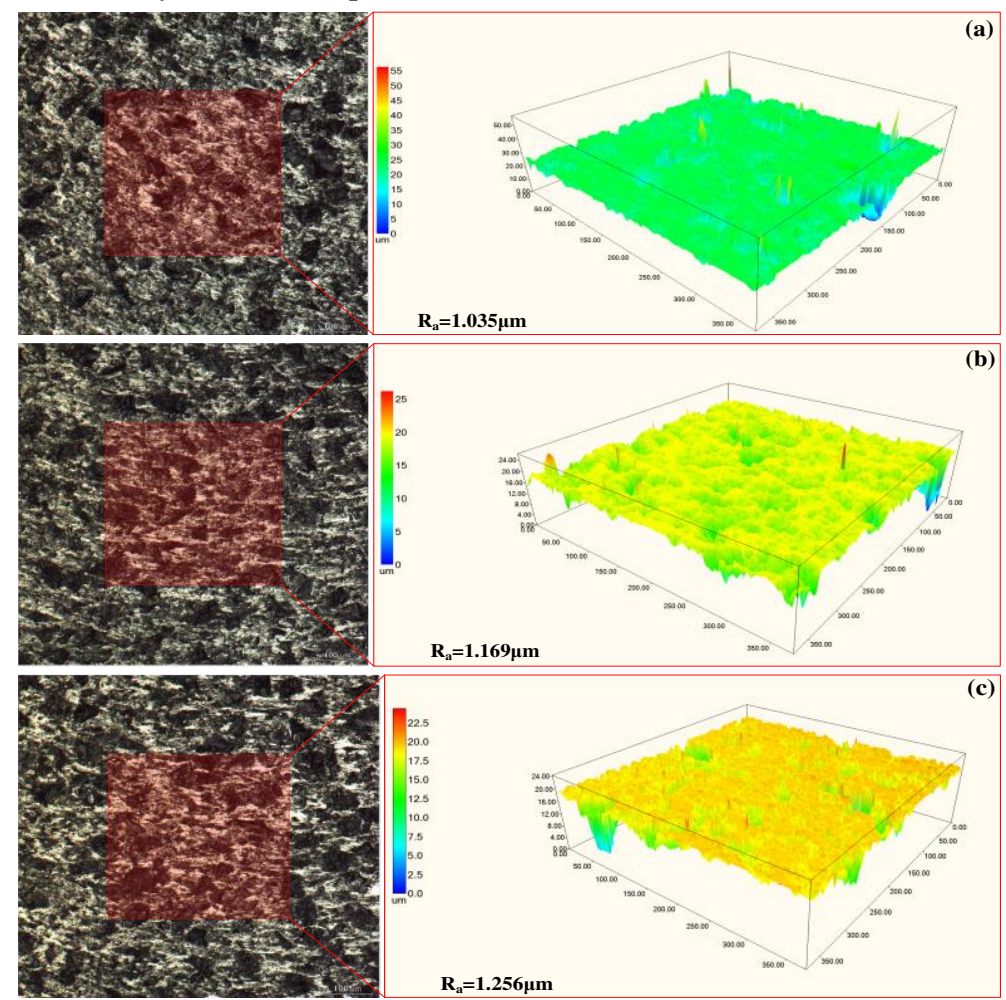

Fig. 12 Micromachined surface topography of SiCp/2024Al composites (a) $N=18000 \mathrm{r} / \mathrm{min}, V_{f}=0.072 \mathrm{~m} / \mathrm{min}, a_{p}=65 \mu \mathrm{m},\left(f_{\mathrm{z}}=4 \mu \mathrm{m}\right) ;$ (b) $N=18000$ $\mathrm{r} / \mathrm{min}, V_{f}=0.108 \mathrm{~m} / \mathrm{min}, a_{p}=65 \mu \mathrm{m},\left(f_{\mathrm{z}}=6 \mu \mathrm{m}\right) ;(\mathrm{c}) N=18000 \mathrm{r} / \mathrm{min}, V_{f}=0.144 \mathrm{~m} / \mathrm{min}, a_{p}=65 \mu \mathrm{m},\left(f_{\mathrm{z}}=8 \mu \mathrm{m}\right)$

As can be seen from Fig. 12, when the feed rate per tooth increases from 4 to $8 \mu \mathrm{m}$, the number of small holes, pits, cracks and burrs on the surface increases significantly, and the surface roughness increases from 1.035 to $1.256 \mu \mathrm{m}$. When the feed rate of each tooth is 4 $\mu \mathrm{m}$, as shown in Fig. 12 (a), the machined surface is relatively smooth. At this time, because the cutting thickness is small, which is smaller than the minimum cutting thickness of aluminum matrix, the size effect of matrix removal is significant, and the coating effect on the surface is strong, and the machined surface is relatively smooth. In addition, the volume of the particles is small, so that the milling force is relatively small, the broken particles are less, the impact on the surface quality is small, so the surface quality is better. Each tooth feeding including increased from $4 \mu \mathrm{m}$ to $6 \mu \mathrm{m}$, 
between substrate size effect is abate, began to appear particle removal, due to the cutting edge radius is bigger, particles are mainly composed of crush removal, under the extrusion of the cutting tool, as the tool of particles under crush slide scratches on the surface, as shown in Fig. 13 (b), surface can see a few scratches. When the feed rate of each tooth increases from $6 \mu \mathrm{m}$ to $8 \mu \mathrm{m}$, the broken part and volume of particles increase, and the milling force increases, which aggravates the wear on the machined surface and tool, resulting in the increase of surface scratches and the deterioration of machining
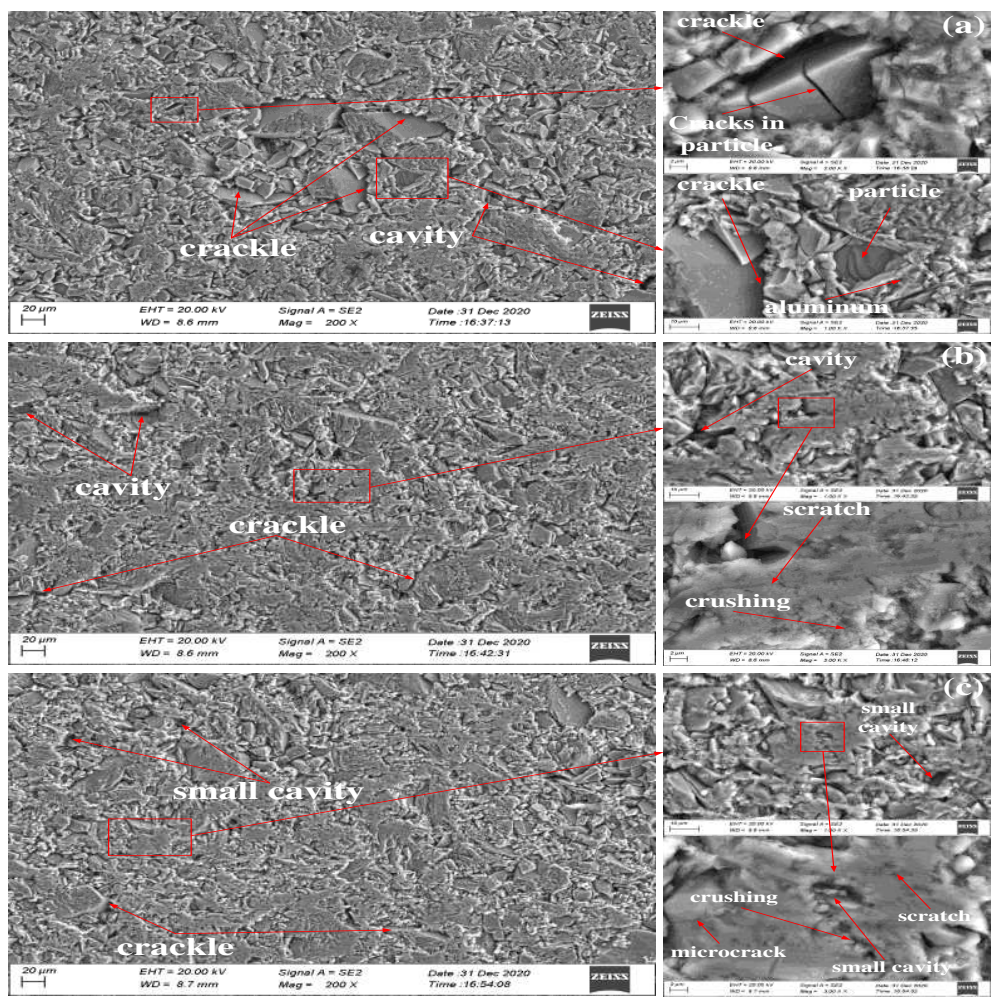

Fig. 13 Micromachined surface defect detection of SiCp/2024Al composites (a) $N=18000 \mathrm{r} / \mathrm{min}, V_{f}=0.072 \mathrm{~m} / \mathrm{min}, a_{p}=65 \mu \mathrm{m},\left(f_{\mathrm{z}}=4 \mu \mathrm{m} / \mathrm{z}\right.$ ); (b) $N=18000 \mathrm{r} / \mathrm{min}, V_{f}=0.108 \mathrm{~m} / \mathrm{min}, a_{p}=65 \mu \mathrm{m},\left(f_{\mathrm{z}}=6 \mu \mathrm{m} / \mathrm{z}\right) ;(\mathrm{c}) N=18000 \mathrm{r} / \mathrm{min}, V_{f}=0.144 \mathrm{~m} / \mathrm{min}, a_{p}=65 \mu \mathrm{m},\left(f_{\mathrm{z}}=8 \mu \mathrm{m} / \mathrm{z}\right)$

When the spindle speed is $18000 \mathrm{r} / \mathrm{min}$, the milling depth is $65 \mu \mathrm{m}$, but the feeding rate is different, the workpiece surface roughness variation trend is shown in Fig. 15.

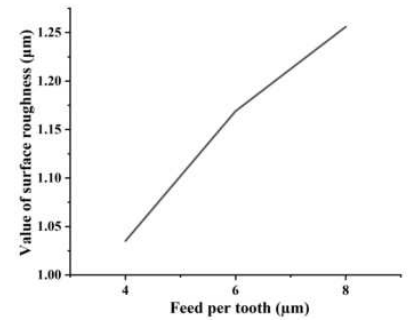

Fig. 15 Surface roughness variation trend

Fig. 13 clearly shows the cracks and cavities caused by the crushing of particles, the scratches caused by the crushing of particles, and the cavities caused by the extrusion of particles. These defects have been clearly shown in the finite element simulation model, and the experimental pictures verify the correctness of the finite element simulation model to a certain extent. Fig. 13 and 15 clearly show that when the feed rate per tooth increases from 4 to $8 \mu \mathrm{m}$, the surface defects of the processed material increase, the surface roughness value increases, the surface consistency decreases, and the surface roughness value increases from 1.035 to 1.256 $\mu \mathrm{m}$. In the process of milling, the milling depth unchanged, with the increase of each tooth feeding, particles per unit time is milling volume increase, 
increase milling force, tool vibration, enhance shed particles as the cutting tool in machining surface rolling and sliding, cause scratches on the surface of the workpiece and empty, the quality of the processing, thus makes the roughness increases.

When the feed rate of each tooth is greater than $6 \mu \mathrm{m}$, the increasing trend of surface roughness becomes slower. This is because with the increase of feed rate of each tooth, the volume of the material to be milled increases, resulting in increased friction, and the effective milling time remains unchanged, most of the heat can not be dissipated, resulting in the softening of the matrix and the reduction of milling force, thus improving the processing quality and weakening the increasing trend.

When the spindle speed is $18000 \mathrm{r} / \mathrm{min}$, the feed rate is $0.108 \mathrm{~m} / \mathrm{min}$ and the milling depth is $65 \mu \mathrm{m}$, the energy spectrum of the surface material of the processed material is shown in Fig. 14.

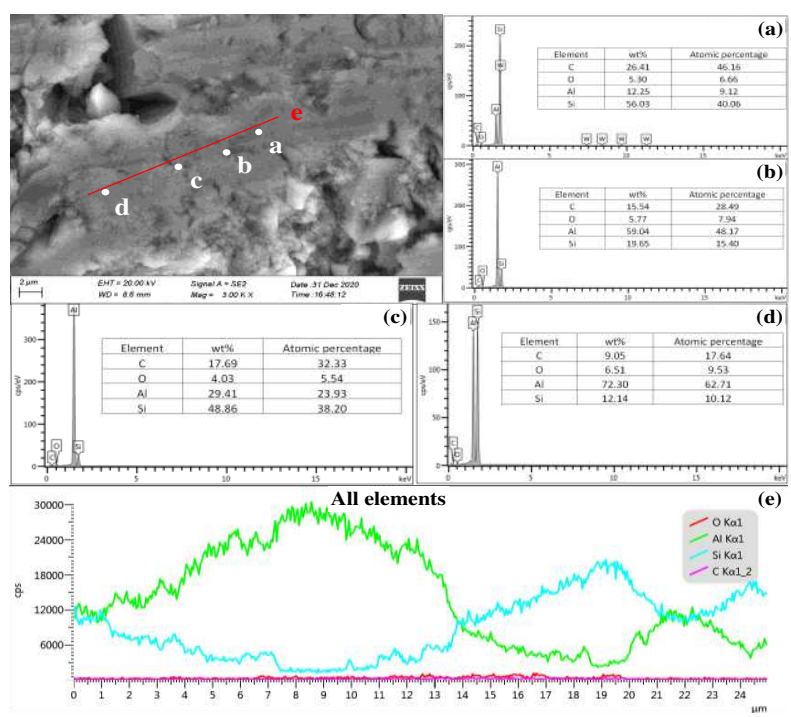

Fig. 14 Surface material detection diagram of composite materials

In addition, the residual chips in the milling process melt on the surface of the workpiece under the action of heat in the system, so that the defects on the surface of the material can be remedied and the surface quality can be improved. According to the detection results in Fig. 16, point a contains $56.03 \% \mathrm{Si}$ element and $12.25 \% \mathrm{Al}$ element, and point $\mathrm{d}$ contains $48.86 \% \mathrm{Si}$ element and $29.41 \% \mathrm{Al}$ element, which can prove that aluminum matrix is attached to $\mathrm{SiC}$ particles.

Considering the particle size $(25 \sim 60 \mu \mathrm{m})$ and the value of feed per tooth, when the feed per tooth is too large, some small particles will be pulled out, resulting in pits on the surface and affecting the machining quality, as shown in Fig. 12 (b) and (c). This is because the particle is milling volume increases, resulting in the increase of milling force, spindle vibration aggravation, resulting in the particle is extruded and broken generated by the crack and cavity, and the particle is pulled out caused by pits and other defects.

The sub-surface damage thickness of the workpiece, the sub-surface damage graph and the sub-surface damage thickness curve of the workpiece are measured, as shown in Fig. 16 and 17.

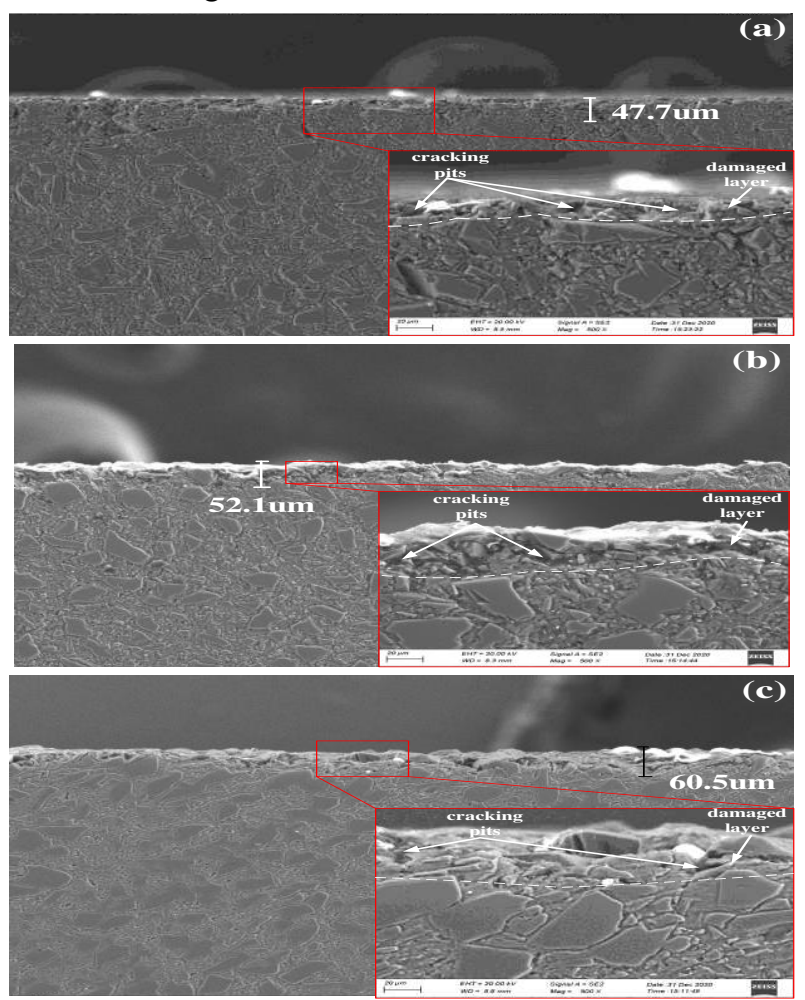

Fig. 16 Detection of subsurface damage of composite materials (a) $N=18000 \mathrm{r} / \mathrm{min}, V_{f}=0.072 \mathrm{~m} / \mathrm{min}, a_{p}=65 \mu \mathrm{m},\left(f_{\mathrm{z}}=4 \mu \mathrm{m} / \mathrm{z}\right) ;(\mathrm{b}) N=18000$ $\mathrm{r} / \mathrm{min}, V_{f}=0.108 \mathrm{~m} / \mathrm{min}, a_{p}=65 \mu \mathrm{m},\left(f_{\mathrm{z}}=6 \mu \mathrm{m} / \mathrm{z}\right)$; (c) $N=18000 \mathrm{r} / \mathrm{min}$, $V_{f}=0.144 \mathrm{~m} / \mathrm{min}, a_{p}=65 \mu \mathrm{m},\left(f_{\mathrm{z}}=8 \mu \mathrm{m} / \mathrm{z}\right)$

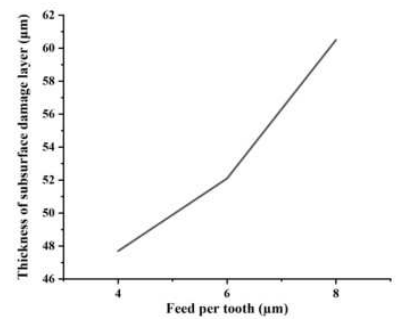

Fig. 17 Thickness variation trend of subsurface damage layer

As can be seen from Fig. 16 of the subsurface damage thickness of the workpiece after end milling, when $f_{z}=4$ $\mu \mathrm{m}$, the thickness of the damage layer is small, and occasionally there are small crack pits or micro-cracks 
on the subsurface. When $f_{z}=6 \mu \mathrm{m}$, the thickness of the damage layer becomes larger, and there are small crack pits, micro cracks and slip layer on the subsurface. When $f_{z}=8 \mu \mathrm{m}$, the thickness of the damaged layer becomes larger again, and pits, cracks and bulges appear on the subsurface.

You can see this in Fig. 17. The thickness of subsurface damage increased from 47.7 to $60.5 \mu \mathrm{m}$ when the feed per tooth increased from 4 to $8 \mu \mathrm{m}$. When the feed per tooth is less than $6 \mu \mathrm{m}$, the thickness of subsurface damage increases slowly. When the feed per tooth is higher than $6 \mu \mathrm{m}$, the thickness of subsurface damage increases rapidly with the increase of the feed per tooth.

This is because with the increase of feed per tooth, the milling force increases, and the SiC particles are more easily broken. This phenomenon can indicate the transition from ductile to brittle grinding with a feed of $6 \mu \mathrm{m}$ per tooth. It can be seen from Fig. 16 (b). With the increase of feed rate per tooth, the thickness of damage layer increases, and the subsurface crack and pit become deeper. This is the transition from ductile to brittle removal. As the feed rate of each tooth continues to increase, the thickness of the damaged layer increases again, and cracks and crack pits also increase, as shown in Fig. 16 (c). At this time, the material is mainly removed through the brittle mode. The condition of subsurface defects also has a great influence on the surface quality.

\section{Conclusion}

In this paper, the removal mechanism of milling $\mathrm{SiCp} / \mathrm{Al}$ composites and the influence of various cutting parameters on surface roughness are studied by the method of simulation and experiment. The following conclusions are drawn through analysis.

In the micro milling process of high volume fraction $\mathrm{SiC}$ based composite materials, the removal forms of particles are pulling out, crushing and pressing, but because the blade diameter of the tool is relatively large to the particles, the removal form of particles is mainly crushing.

There are many pits on the surface of the workpiece when the particles are peeled off the matrix. Some SiC particles are pressed by the cutting tool, such as the aluminum alloy matrix, and some residual broken particles are found in the pits.These defects have been clearly demonstrated in the heterogeneous finite element simulation model, and the correctness of the simulation model has been further verified by experiments.

Through simulation and experimental analysis, it is concluded that the cutting thickness increases, and the material surface quality becomes worse; With the increase of milling depth, the surface quality of material becomes better.With the increase of feed rate per tooth, the material surface defects increase and the surface quality becomes worse. At the same time, the thickness of subsurface damage layer increases, and the cracks and pits become deeper.

In the milling process of $\mathrm{SiCp} / \mathrm{Al}$ composites with meso-scale tool, the surface defects mainly include cavity, crack and delamination caused by extrusion of aluminum matrix.The minimum cutting thickness of $\mathrm{SiCp} / \mathrm{Al}$ composites is less than or equal to $4 \mu \mathrm{m}$, and its ratio to the radius of the cutting edge circle should be less than or equal to $4 \%$.

\section{Ethical Approval}

This research project has been approved by the Ethics Committee of Liaoning University of Technology.

\section{Consent to Participate}

I solemnly declare that the paper "Study on removal mechanism and surface quality of high volume fraction $\mathrm{SiCp} / \mathrm{Al}$ composites based on meso-scale" presented by us is the result of our research. This paper does not contain any work published or written by any other individual or group, except for the content specifically noted and cited in the paper. I fully realize that the legal consequences of this statement shall be borne by me

\section{Consent to Publish The Author confirms:}

that the work described has not been published before; that it is not under consideration for publication elsewhere;

that its publication has been approved by all co-authors, if any;

that its publication has been approved by the responsible authorities at the institution where the work 
is carried out.

The Author agrees to publication in the Journal indicated below and also to publication of the article in English by Springer in Springer's corresponding English-language journal. The copyright to the English-language article is transferred to Springer effective if and when the article is accepted for publication. The author warrants that his/her contribution is original and that he/she has full power to make this grant. The author signs for and accepts responsibility for releasing this material on behalf of anyand all co-authors. The copyright transfer covers the exclusive right to reproduce and distribute the article, including reprints, translations, photographic reproductions, microform, electronic form or any other reproductions of similar nature. After submission of the agreement signed by the corresponding author, changes of authorship or in the order of the authors listed will not be accepted by Springer. Journal: The International Journal of Advanced Manufacturing Technology, chemical samples Names of ALL contributing authors: Po Jin, Qi Gao, Quanzhao Wang, and Wenbo Li

\section{Declarations Funding}

This work was supported by the National Natural Science Foundation of China (No.51775100) and the Doctoral Start-up Fund of Liaoning Province (2019-BS-123).

\section{Conflicts of interest/Competing interests}

The authors have declared that no conflict of interest exists.

\section{Availability of data and material}

The data used to support the findings of this study are available from the corresponding author upon request.

\section{Authors' contributions}

The finite element simulation experiment of micromilling of $\mathrm{SiCp} / \mathrm{Al}$ composites was established. The milling process of $\mathrm{SiCp} / \mathrm{Al}$ composites with high volume fraction and large grain size was studied. The distribution of stress and strain of $\mathrm{SiC}$ reinforced particles and the material removal mechanism were analyzed. The influence degree of each influencing factor on surface roughness.

\section{Compliance with ethical standards}

Ethical statement Authors state that the research was conducted according to ethical standard.

\section{Acknowledgment}

The authors would like to express their gratitude to the reviewers of the manuscript for their valuable suggestions and comments.

\section{Reference}

1. Wang T, Xie LJ, Wang XB (2015) Simulation study on defect formation mechanism of the machined surface in milling of high volume fraction $\mathrm{SiCp} / \mathrm{Al}$ composite[J]. Int J Adv Manuf Tech, 79(5-8):1185- 1194

2. Teng XY, Huo DH, Chen WQ, Wong E, Zheng L, I. Shyha (2018) Finite element modelling on cutting mechanism of nano $\mathrm{Mg} / \mathrm{SiC}$ metal matrix composites considering cutting edge radius[J]. J Manuf Process,32 (APR.) :116-126.

3. Niu ZC, Cheng K (2019) An experimental investigation on surface generation in ultraprecision machining of particle reinforced metal matrix composites[J]. Int J Adv Manuf Tech, 105(8):4499-4507.

4. N. Suresh Kumar Reddy, Shin Kwang-Sup, Yang MY (2008) Experimental study of surface integrity during end milling of $\mathrm{Al} / \mathrm{SiC}$ particulate metal-matrix composites[J]. Int $\mathrm{J}$ Adv Manuf Tech, 201(1-3):574- 579.

5. Pramanik A, Basak AK, Dong Y, Subramaniam S, Littlefair G (2018) Milling of Nanoparticles Reinforced Al-Based Metal Matrix Composites[J]. J. Compos Sci, 2(1):13.

6. Dabade UA, Jadhav MR (2016) Experimental Study of Surface Integrity of $\mathrm{Al} / \mathrm{SiC}$ Particulate Metal-matrix Composites in Hot Machining[J]. Procedia Cirp, 41:914-919.

7. Ghoreishi R, Roohi AH, Ghadikolaei AD (2019) Evaluation of tool wear in high-speed face milling of $\mathrm{Al} / \mathrm{SiC}$ metal matrix composites[J]. J Braz Soc Mech Sci, 41:146.

8. Liu JW, Cheng K, Ding H, Chen SJ (2020) An analytical model for force prediction in micromilling silicon carbide particle-reinforced aluminum matrix composites[J]. P I Mech Eng B-J Eng, 234(10): 095440542092341

9. Deng B, Peng FY, Zhou L, Wang HW, Yang MH, Yan R (2020) A comprehensive study on flank wear progression of polycrystalline diamond micro-tool during micro end-milling of $\mathrm{SiCp} / \mathrm{Al}$ composites[J]. Wear, 456-457:203291. 
10.Wang BB, Xie LJ, Chen XL, Wang XB (2016) The milling simulation and experimental research on high volume fraction of $\mathrm{SiCp} / \mathrm{Al}[\mathrm{J}]$. Int $\mathrm{J} \mathrm{Adv}$ Manuf Tech, 82(5-8):809-816.

11.Wang T, Xie LJ, Wang XB, Ding ZW (2015) PCD tool performance in high-speed milling of high volume fraction $\mathrm{SiCp} / \mathrm{Al}$ composites[J]. Int $\mathrm{J} \mathrm{Adv}$ Manuf Tech, 78:1445-1453.

12.Bian R, He N, Li L, Zhan ZB, Wu Q, Shi ZY (2013) Precision milling of high volume fraction $\mathrm{SiCp} / \mathrm{Al}$ composites with monocrystalline diamond end mill[J]. Int $\mathrm{J}$ Adv Manuf Tech, 71(1-4):411-419.

13.Zhao GL, Mao PC, Li L, Iqbal A, He N (2020) Micro-milling of $65 \mathrm{vol} \% \mathrm{SiCp} / \mathrm{Al}$ composites with a novel laser-assisted hybrid process[J]. Ceram Int, 46(16): 26121- 26128.

14.Gavalda Diaz O, Axinte DA, Butler-Smith P, Novovic D (2019) On understanding the micro-structure of $\mathrm{SiC} / \mathrm{SiC}$ Ceramic Matrix Composites (CMCs) after a material removal process[J]. Mat Sci Eng R, 743(JAN.16):1-11.

15.Quan YM, Ye BY (2003) The effect of machining on the surface properties of $\mathrm{SiC} / \mathrm{Al}$ composites[J]. J Mater Process Tech, 138(1-3):464- 467.

16.Teng XY, Chen WQ, Huo DH, I. Shyha, Lin C (2018) Comparison of cutting mechanism when machining micro and nano-particles reinforced $\mathrm{SiC} / \mathrm{Al}$ metal matrix composites[J]. Compos Struct, 203(NOV.): 636-647.

17.Setia S, Chauhan SR (2021) Experimental Investigation and Comparison of Output Cutting Regimes with Finite Element Machining Models for SiCp Based Al7075 Composite[J]. Silicon-Neth, DOI: 10.1007/s 12633-020-00887-3.

18.Lu SJ, Li ZQ, Zhang JJ, Zhang JG, Wang XH, Yan YD, Sun T (2020) Finite Element Investigation of the Influence of SiC Particle Distribution on Diamond Cutting of $\mathrm{SiCp} / \mathrm{Al}$ Composites[J]. Nanomanufacturing and Metrology: 1-9.

19.Lu SJ, Zhang JJ, Li ZQ, Zhang JG, Wang XH, Hartmaier A, Xu JF, Yan YD, Sun T (2020) Cutting path-dependent machinability of $\mathrm{SiCp} / \mathrm{Al}$ composite under multi-step ultra-precision diamond cutting[J]. Chinese J Aeronaut, 2020, 34(4):241-252.

20.Li YQ, Xiang DH, Feng HR, Gao GF, Shi ZL (2020) Surface characteristics investigation of ultrasonic longitudinal- torsional milling of high-volume fraction $\mathrm{SiCp} / \mathrm{Al}[\mathrm{J}]$. Int J Adv Manuf Tech, 110(6):1-12.
21.Wang JF, Pan LJ, Bian YJ, Lu YQ (2020) Experimental Investigation of the Surface Roughness of Finish-Machined High Volume Fraction SiCp/Al Composites[J]. Arab J Sci Eng 45:5399-5406

22.Laghari RA, Li JG, Mia M (2020) Effects of Turning Parameters and Parametric Optimization of the Cutting Forces in Machining $\mathrm{SiCp} / \mathrm{Al} 45 \mathrm{wt} \%$ Composite[J]. Metals-Basel, 10(6):840.

23.Ramesh MV, Chan KC, Lee WB, Cheung CF (2001) Finite-element analysis of diamond turning of aluminium matrix composites[J]. Compos Sci Technol, 61(10): 1449-1456.

24.Chavoshi SZ, Goel S, Morantz P (2019) Current trends and future of sequential micro-machining processes on a single machine tool[J]. Mater Design, 127(aug.): 37-53. 


\section{Figures}

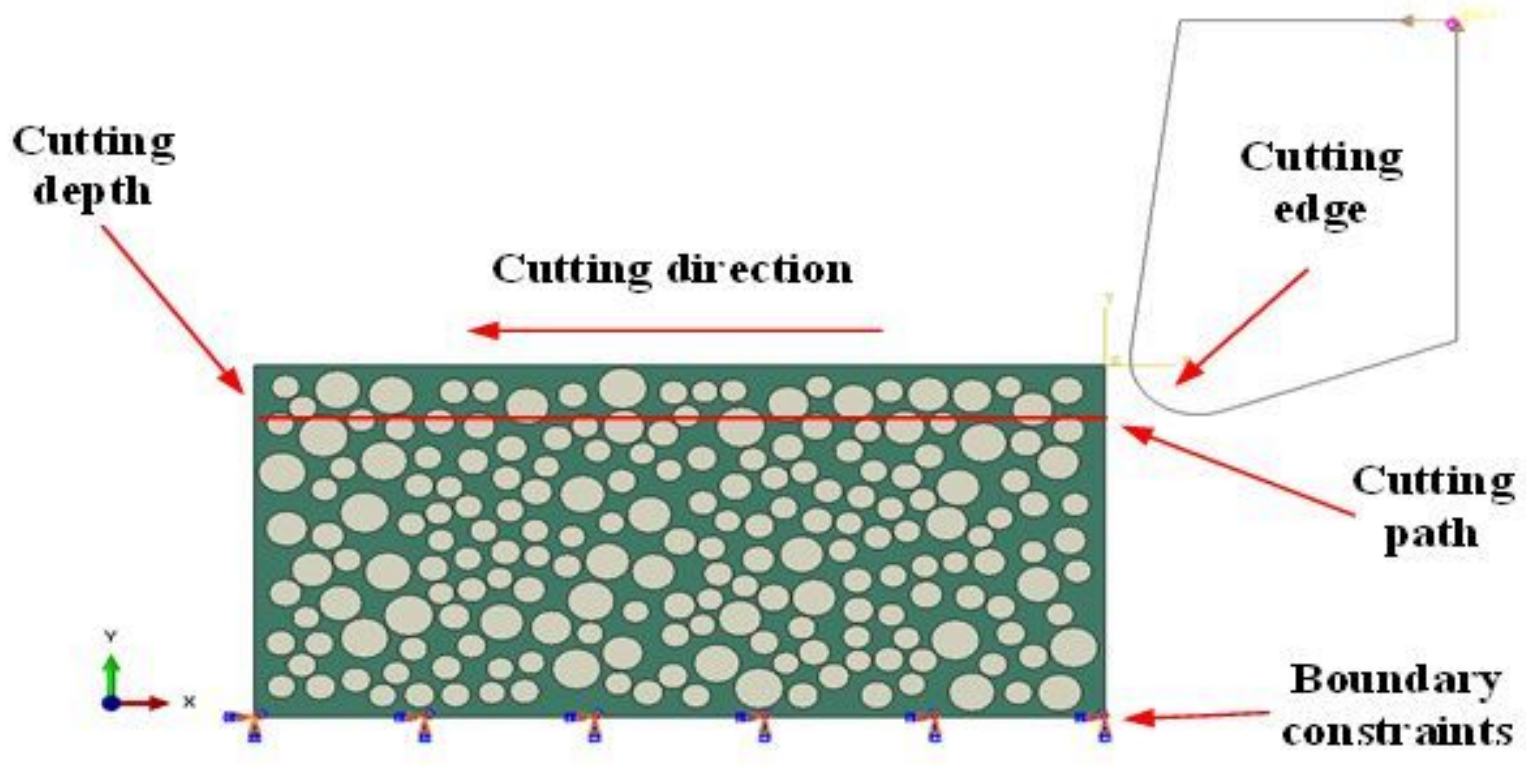

Figure 1

Schematic diagram of the milling model

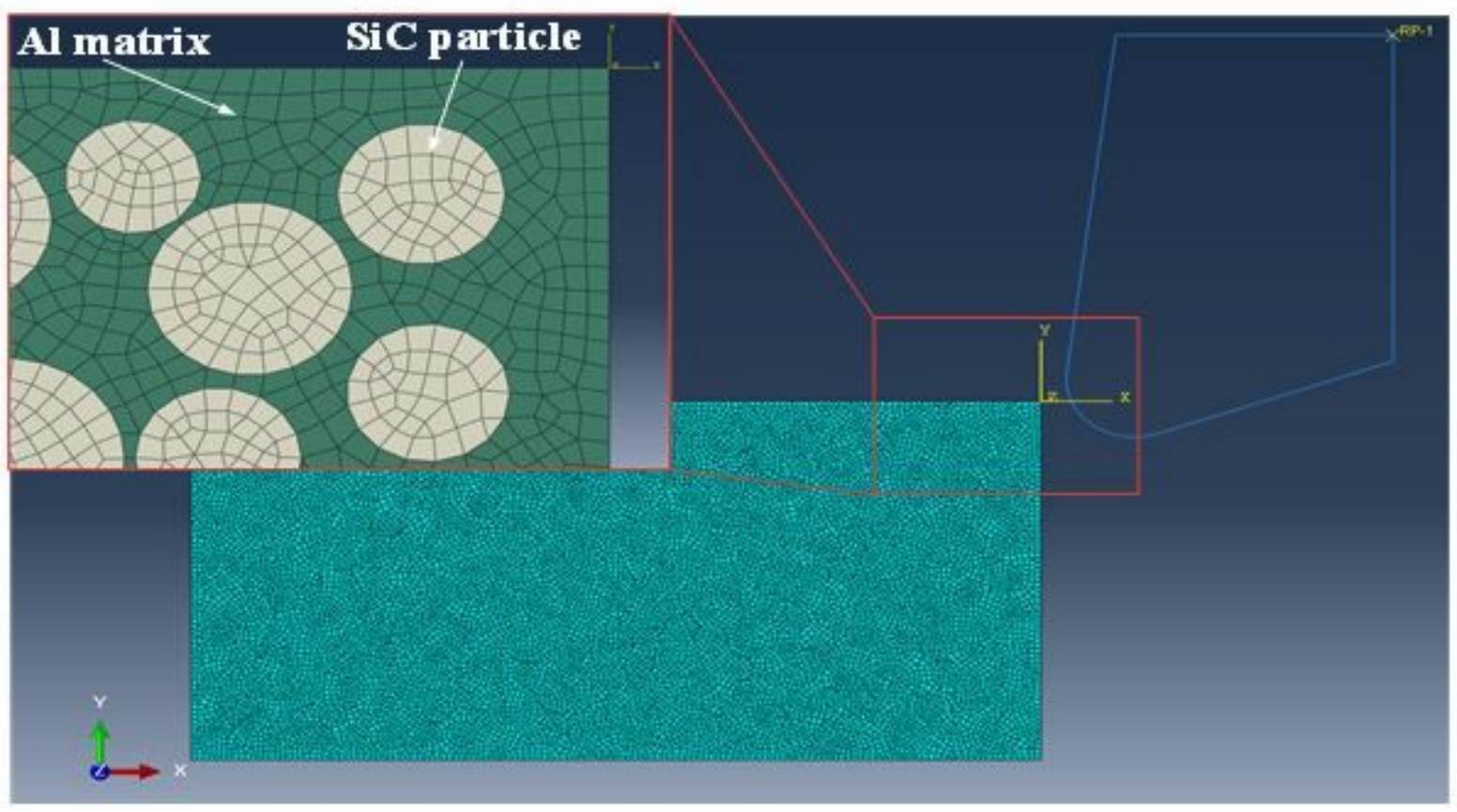

Figure 2

Mesh division in the simulation model 
Tool feed direction

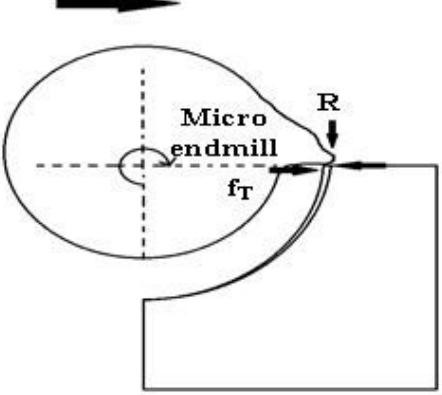

(a)

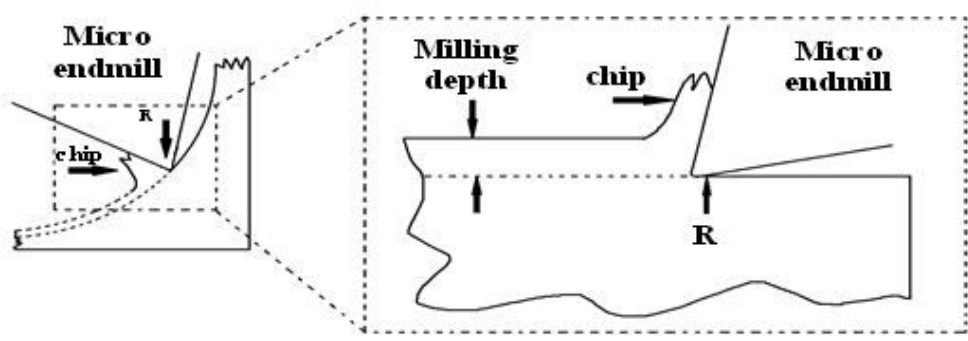

\section{Figure 3}

(a) Two-dimensional milling process diagram when the tool rotates $180^{\circ}$; (b) Relationship between 2D milling process and orthogonal machining process.

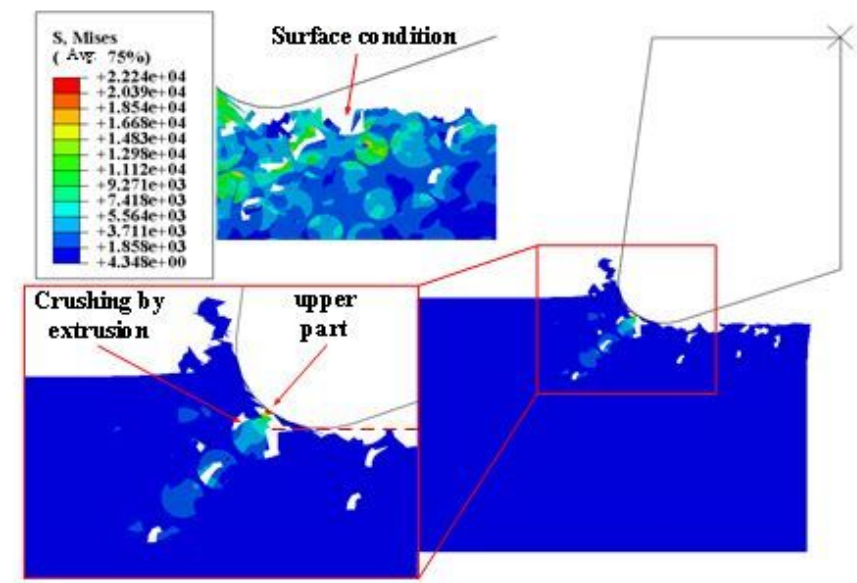

(a)
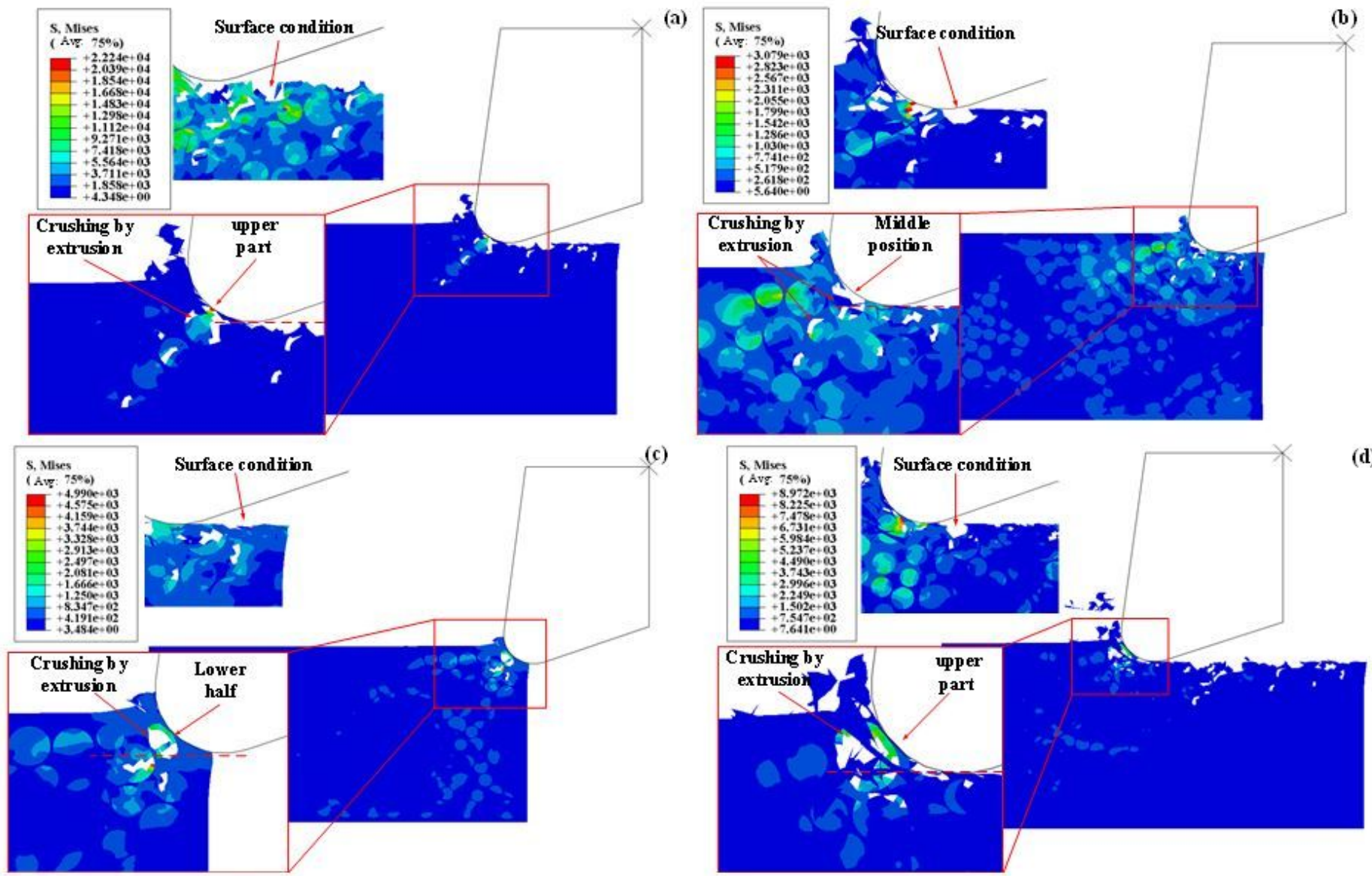

Figure 4

Particle removal mode and stress distribution 


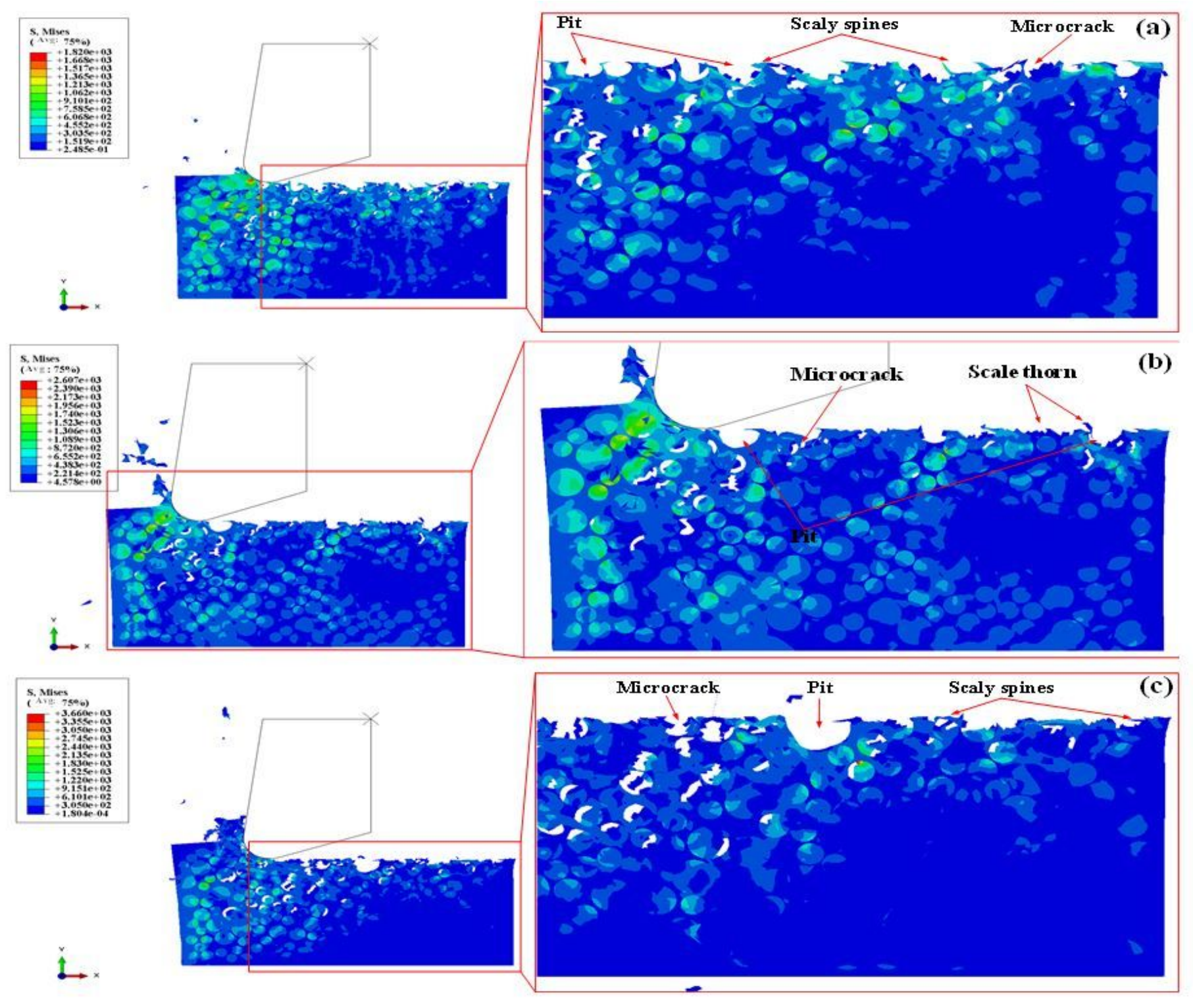

\section{Figure 5}

Microstructure and stress distribution of workpiece surface (a) N=18000 r/min, $\mathrm{Vc}=2826 \mathrm{~mm} / \mathrm{s}, \mathrm{h}=25$ $\mu \mathrm{m}$; (b) $\mathrm{N}=18000 \mathrm{r} / \mathrm{min}, \mathrm{Vc}=2826 \mathrm{~mm} / \mathrm{s}, \mathrm{h}=45 \mu \mathrm{m}$; (c) $\mathrm{N}=18000 \mathrm{r} / \mathrm{min}, \mathrm{Vc}=2826 \mathrm{~mm} / \mathrm{s}, \mathrm{h}=65 \mu \mathrm{m}$
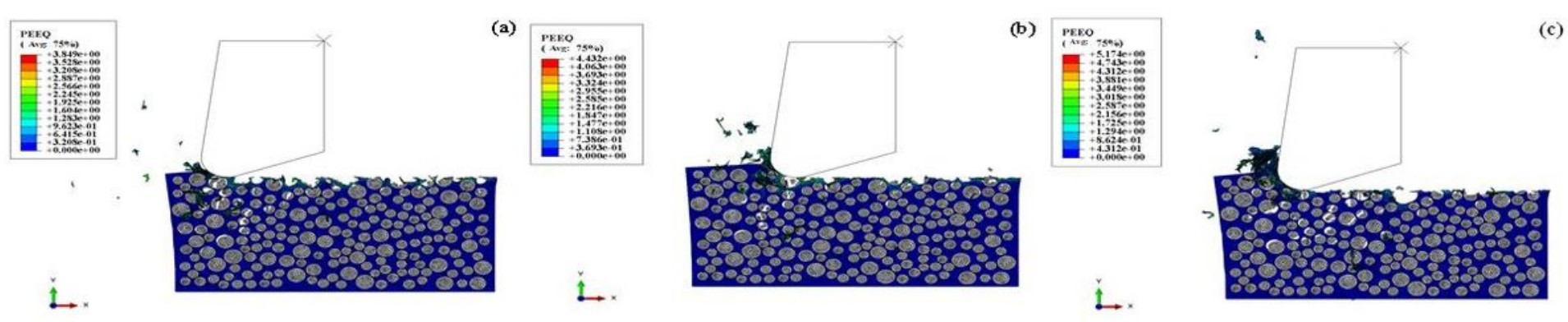

Figure 6 
Equivalent plastic strain distribution (a) $\mathrm{N}=18000 \mathrm{r} / \mathrm{min}, \mathrm{Vc}=2826 \mathrm{~mm} / \mathrm{s}, \mathrm{h}=25 \mu \mathrm{m}$; (b) $\mathrm{N}=18000 \mathrm{r} / \mathrm{min}$, $V_{c}=2826 \mathrm{~mm} / \mathrm{s}, \mathrm{h}=45 \mu \mathrm{m}$; (c) N=18000 r/min, $V_{c}=2826 \mathrm{~mm} / \mathrm{s}, \mathrm{h}=65 \mu \mathrm{m}$

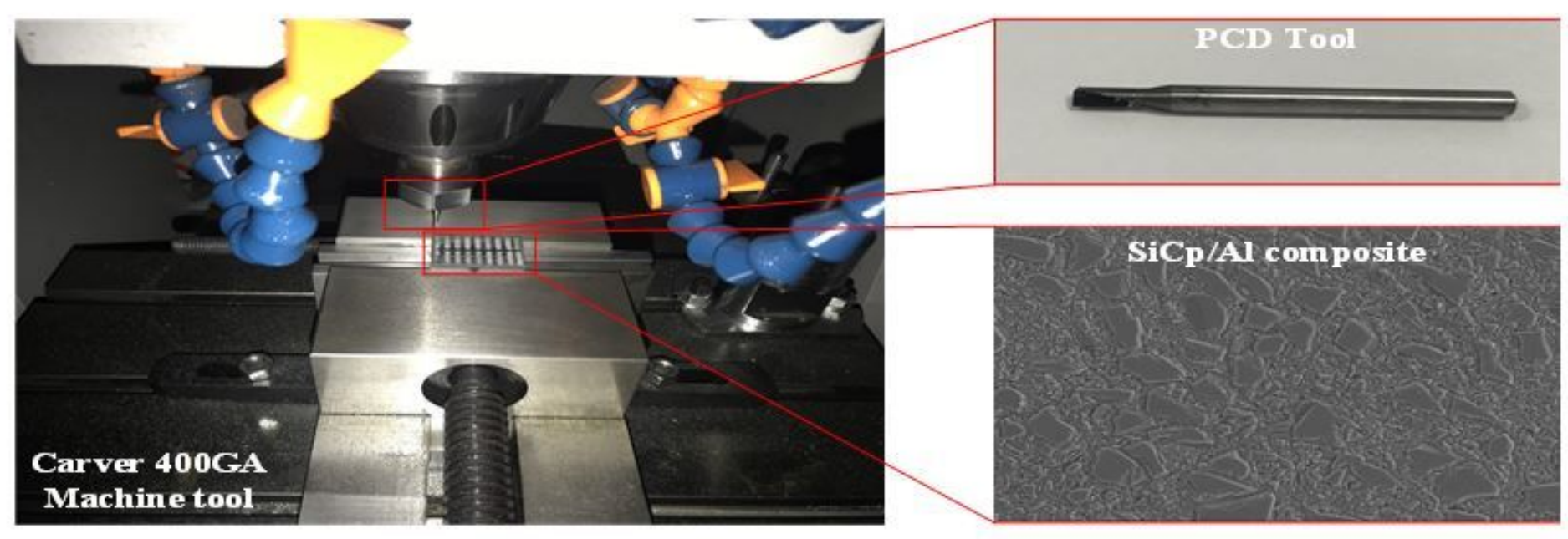

\section{Figure 7}

Experimental site
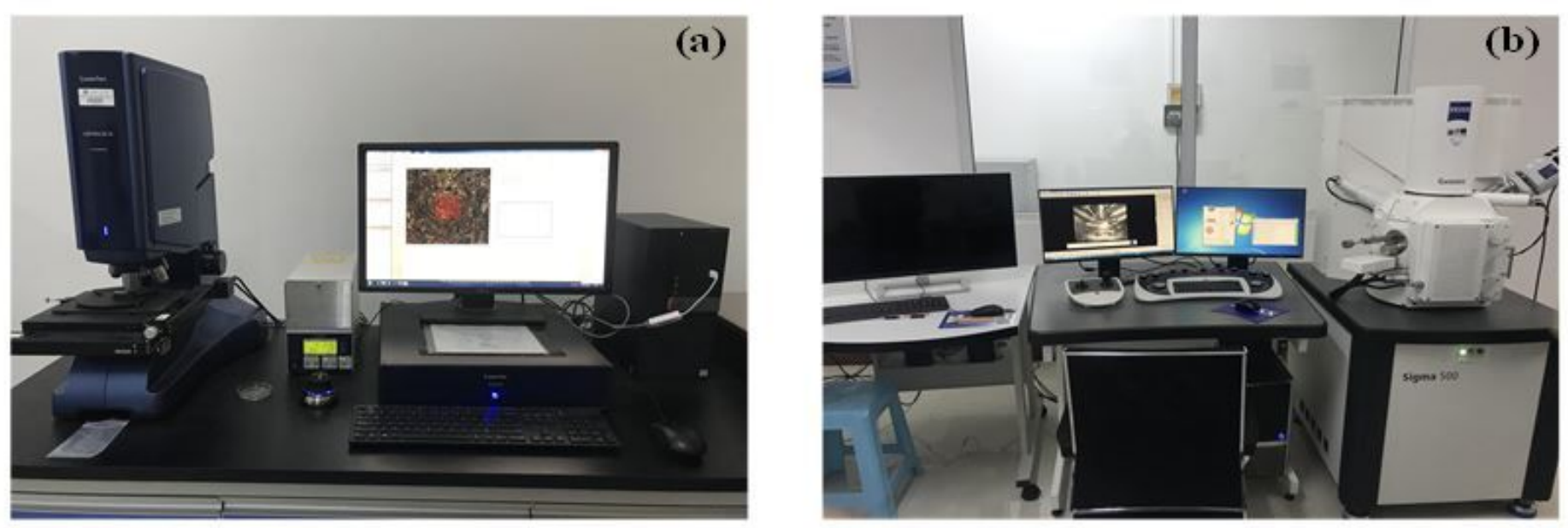

Figure 8

Detection equipment (a) true color confocal microscope; (b)Zeiss Sigma 500 field emission scanning electron microscope 

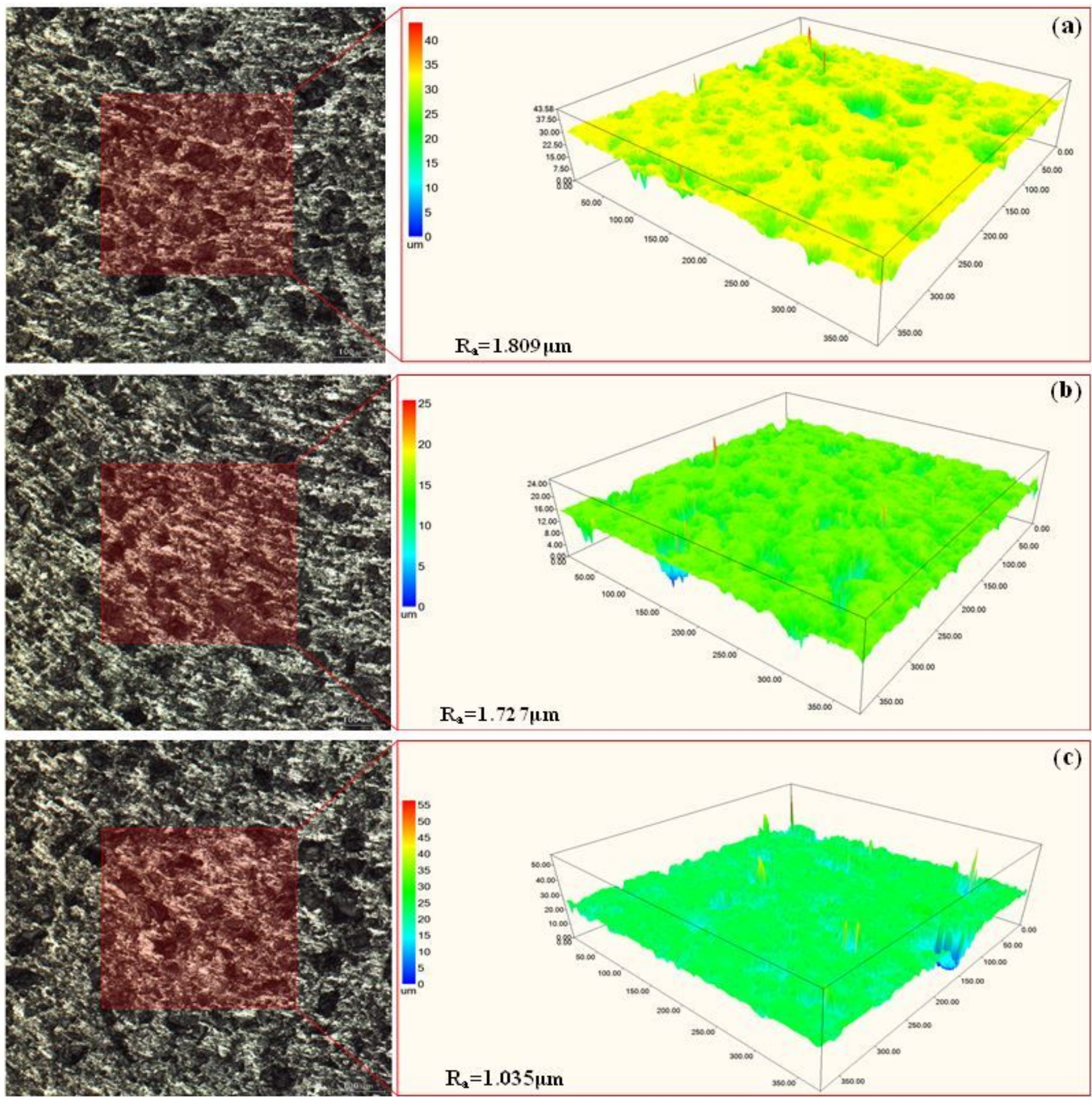

\section{Figure 9}

Machined surface topography of SiCp/2024Al composites (a) N=18000 r/min, Vf=0.072 m/min, ap=25 $\mu \mathrm{m}$; (b) $\mathrm{N}=18000 \mathrm{r} / \mathrm{min}, \mathrm{Vc}=0.072 \mathrm{~m} / \mathrm{min}, \mathrm{ap}=45 \mu \mathrm{m}$; (c) $\mathrm{N}=18000 \mathrm{r} / \mathrm{min}, \mathrm{Vf}=0.072 \mathrm{~m} / \mathrm{min}, \mathrm{ap}=65 \mu \mathrm{m}$; 


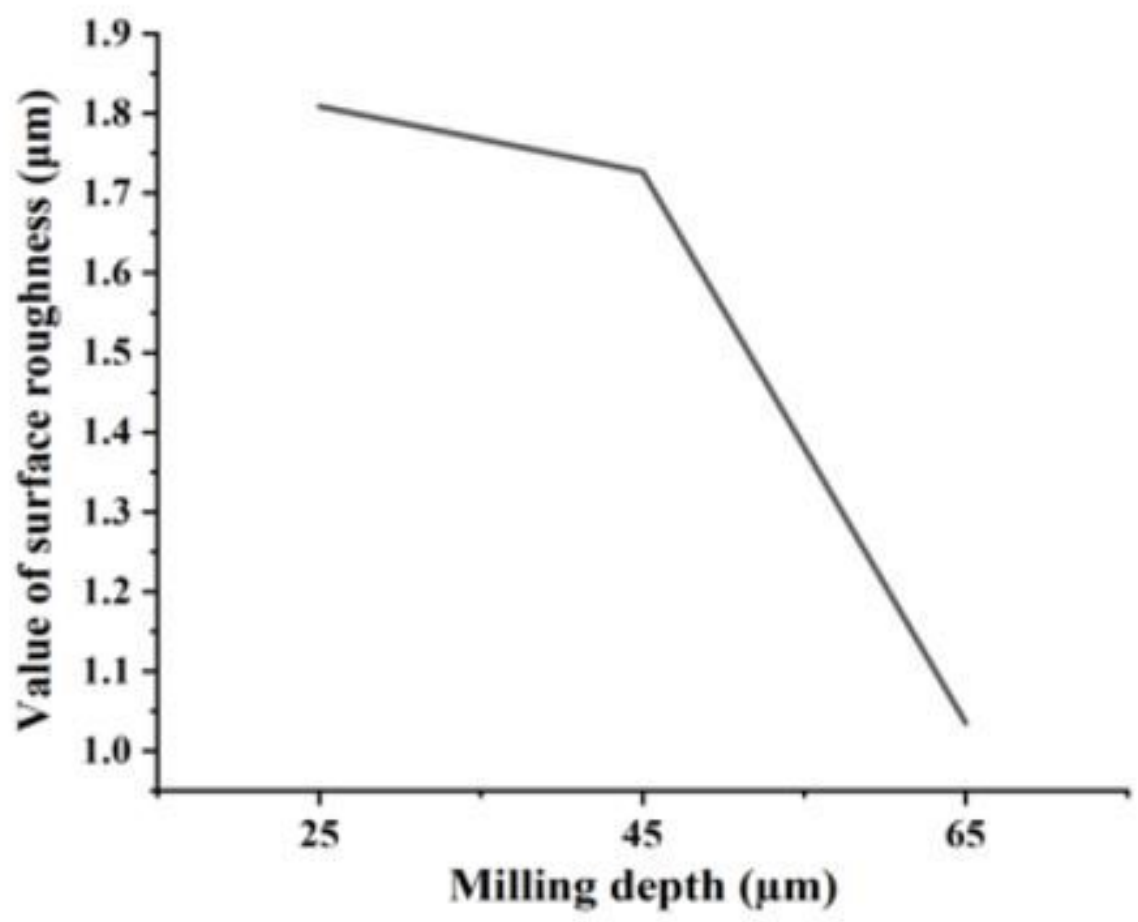

Figure 10

Surface roughness variation trend 

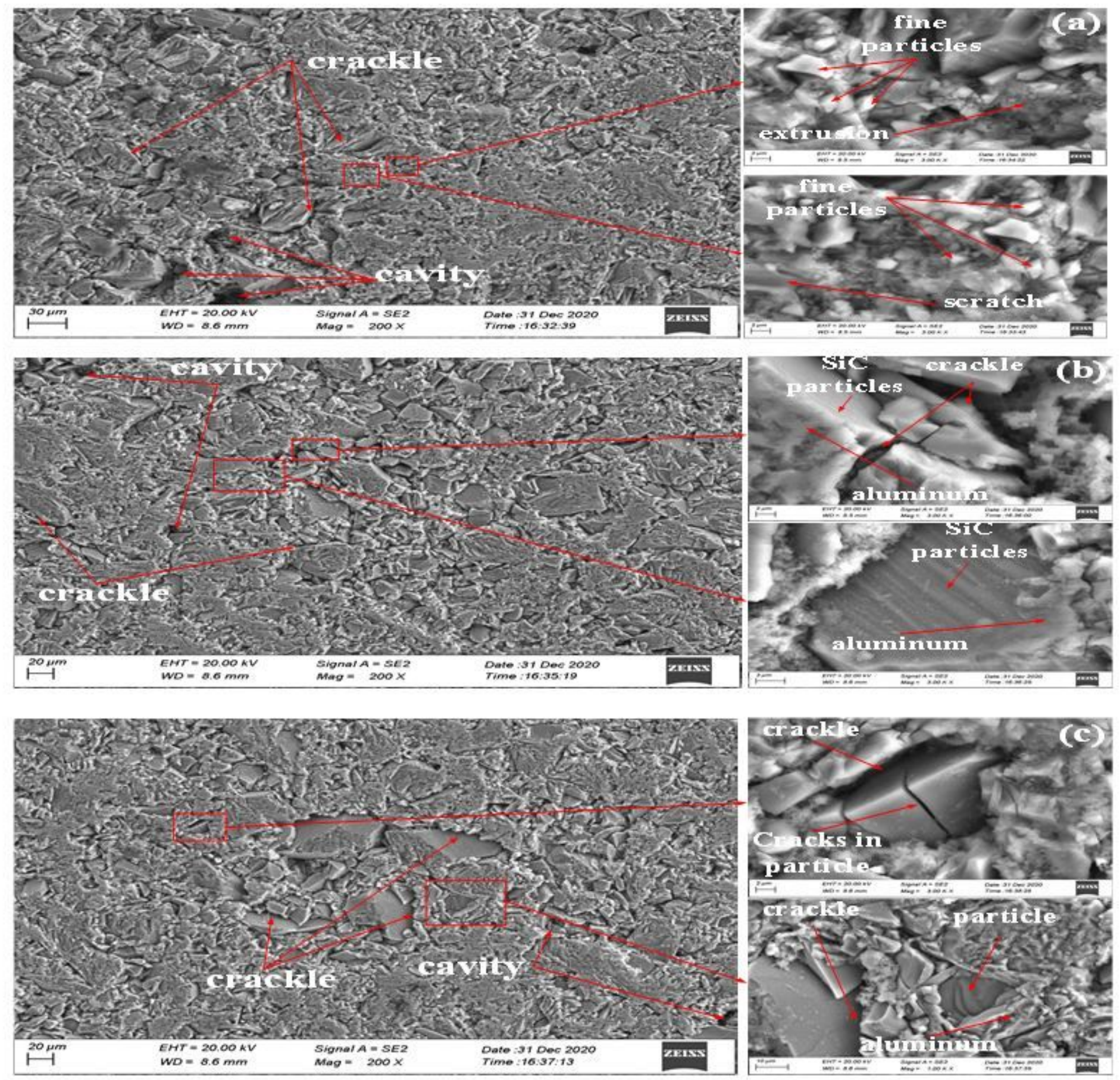

\section{Figure 11}

Surface defect detection of machined materials (a) $\mathrm{N}=18000 \mathrm{r} / \mathrm{min} \square \mathrm{Vf}=0.072 \mathrm{~m} / \mathrm{min} \square \mathrm{ap}=25 \mu \mathrm{m}$; (b) $\mathrm{N}=18000 \mathrm{r} / \mathrm{min} \square \mathrm{Vf}=0.072 \mathrm{~m} / \mathrm{min} \square a p=45 \mu \mathrm{m}$; (c) N=18000 $\mathrm{r} / \mathrm{min} \square \mathrm{Vf}=0.072 \mathrm{~m} / \mathrm{min} \square a p=65 \mu \mathrm{m}$; 

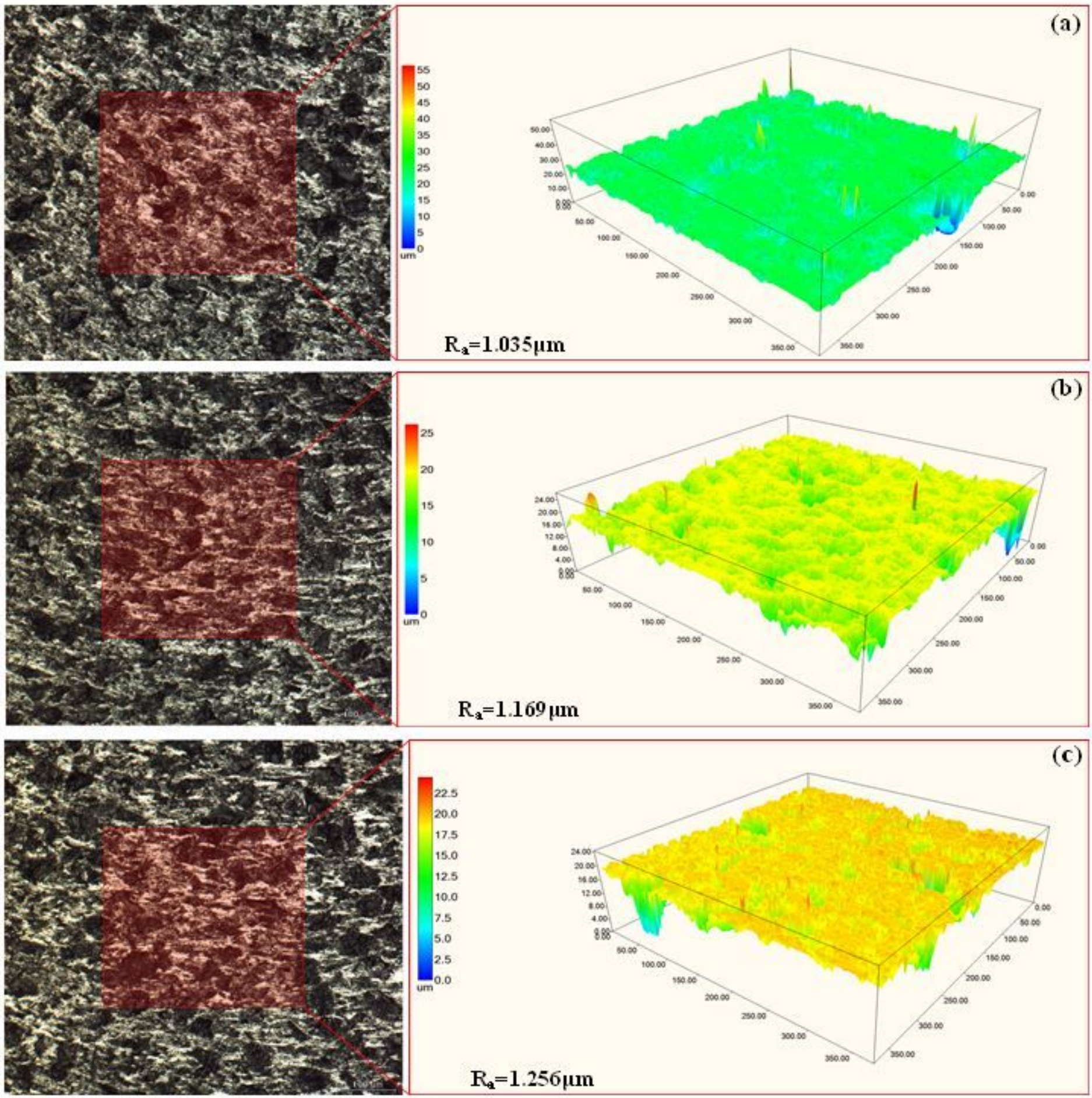

(c)

Figure 12

Micromachined surface topography of SiCp/2024Al composites (a) $\mathrm{N}=18000 \mathrm{r} / \mathrm{min}, \mathrm{Vf}=0.072 \mathrm{~m} / \mathrm{min}$, ap $=65 \mu \mathrm{m},(\mathrm{fz}=4 \mu \mathrm{m}) ;(\mathrm{b}) \mathrm{N}=18000 \mathrm{r} / \mathrm{min}, \mathrm{Vf}=0.108 \mathrm{~m} / \mathrm{min}, \mathrm{ap}=65 \mu \mathrm{m},(\mathrm{fz}=6 \mu \mathrm{m}) ;(\mathrm{c}) \mathrm{N}=18000 \mathrm{r} / \mathrm{min}$, $\mathrm{Vf}=0.144 \mathrm{~m} / \mathrm{min}, \mathrm{ap}=65 \mu \mathrm{m},(\mathrm{fz}=8 \mu \mathrm{m})$ 

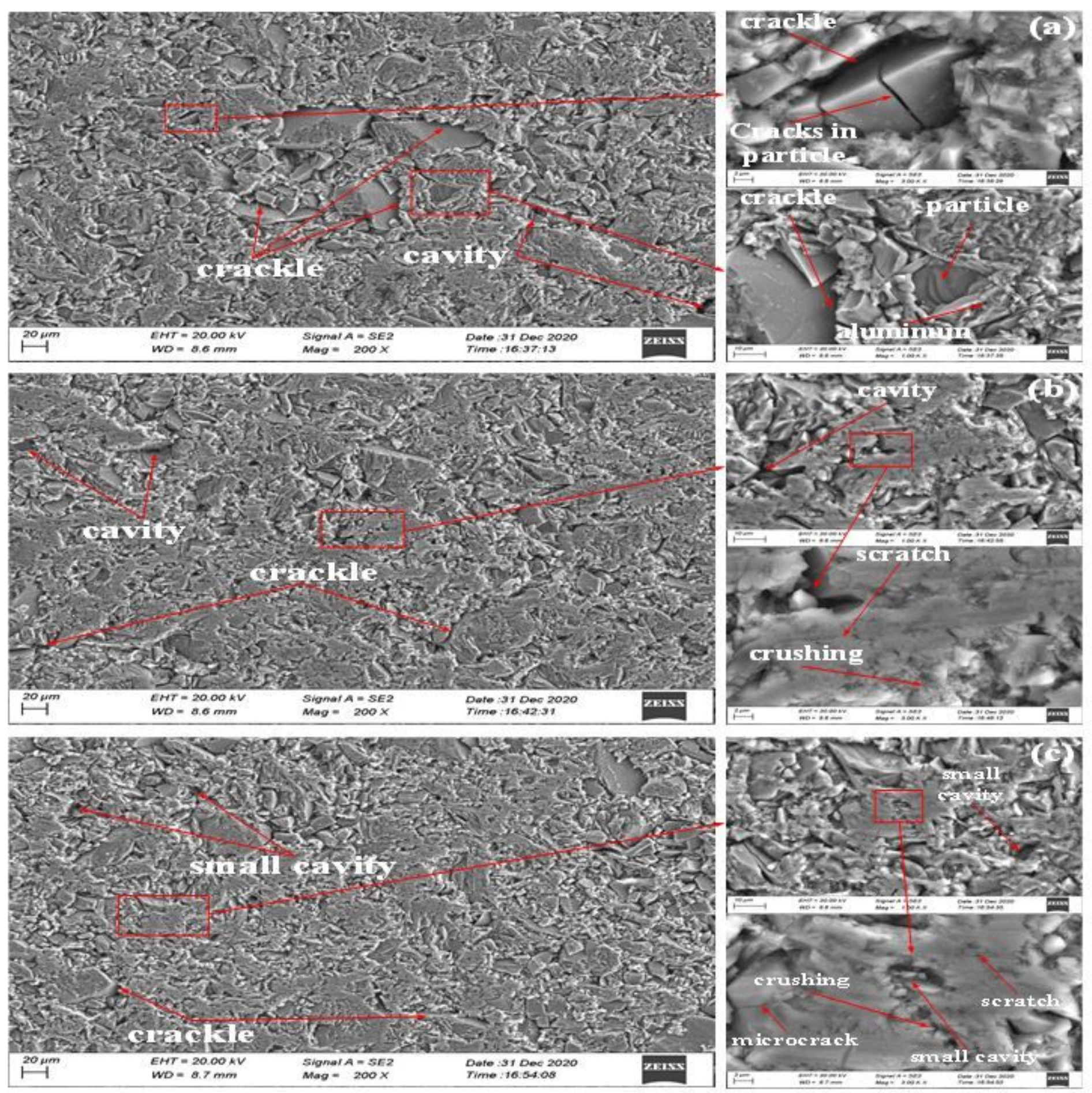

\section{Figure 13}

Micromachined surface defect detection of SiCp/2024Al composites (a) N=18000 r/min, $\mathrm{Vf}=0.072$ $\mathrm{m} / \mathrm{min}, \mathrm{ap}=65 \mu \mathrm{m},(\mathrm{fz}=4 \mu \mathrm{m} / \mathrm{z}) ;(\mathrm{b}) \mathrm{N}=18000 \mathrm{r} / \mathrm{min}, \mathrm{Vf}=0.108 \mathrm{~m} / \mathrm{min}, \mathrm{ap}=65 \mu \mathrm{m},(\mathrm{fz}=6 \mu \mathrm{m} / \mathrm{z}) ;(\mathrm{c})$ $\mathrm{N}=18000 \mathrm{r} / \mathrm{min}, \mathrm{Vf}=0.144 \mathrm{~m} / \mathrm{min}, \mathrm{ap}=65 \mu \mathrm{m},(\mathrm{fz}=8 \mu \mathrm{m} / \mathrm{z})$ 

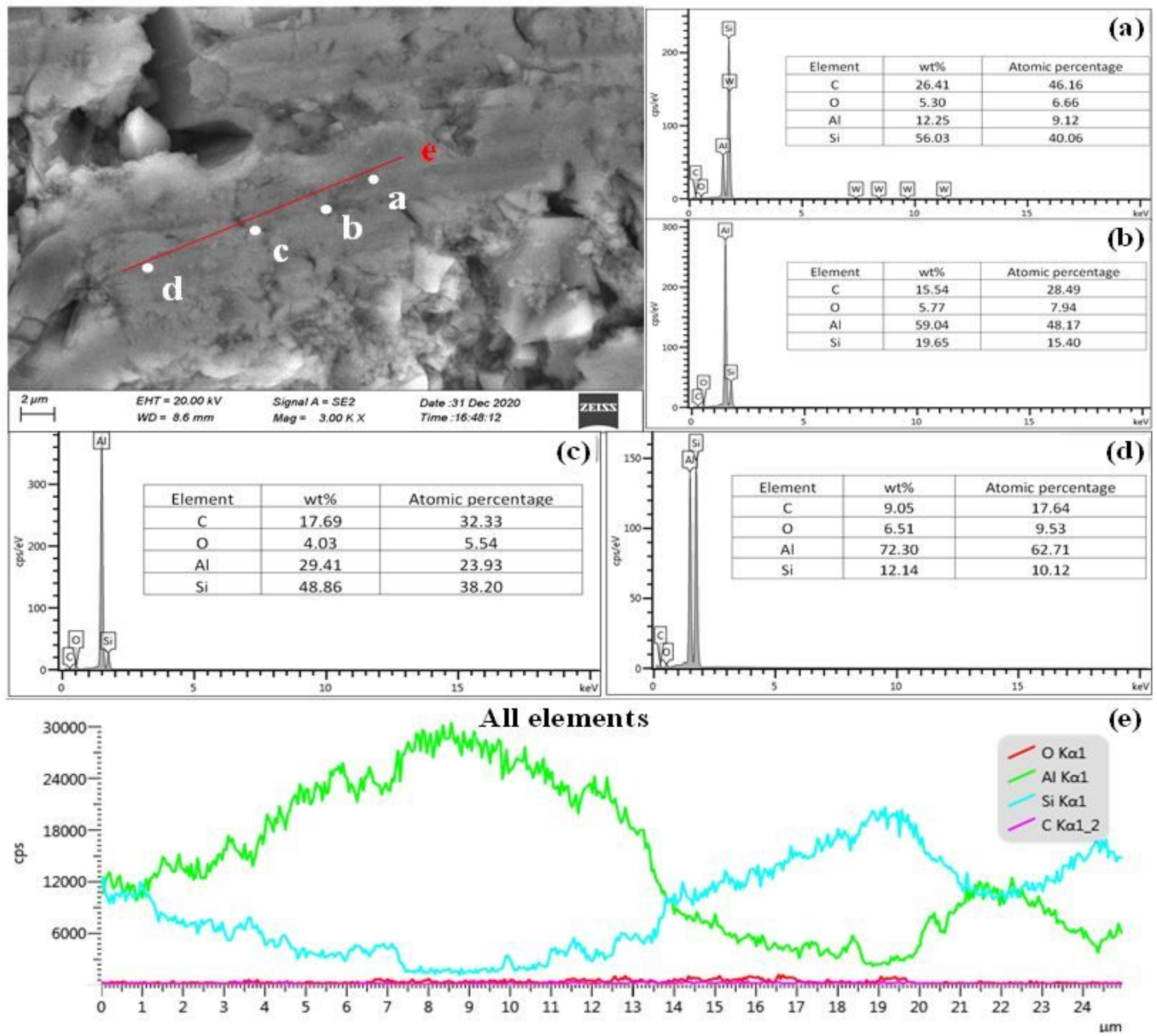

Figure 14

Surface material detection diagram of composite materials 


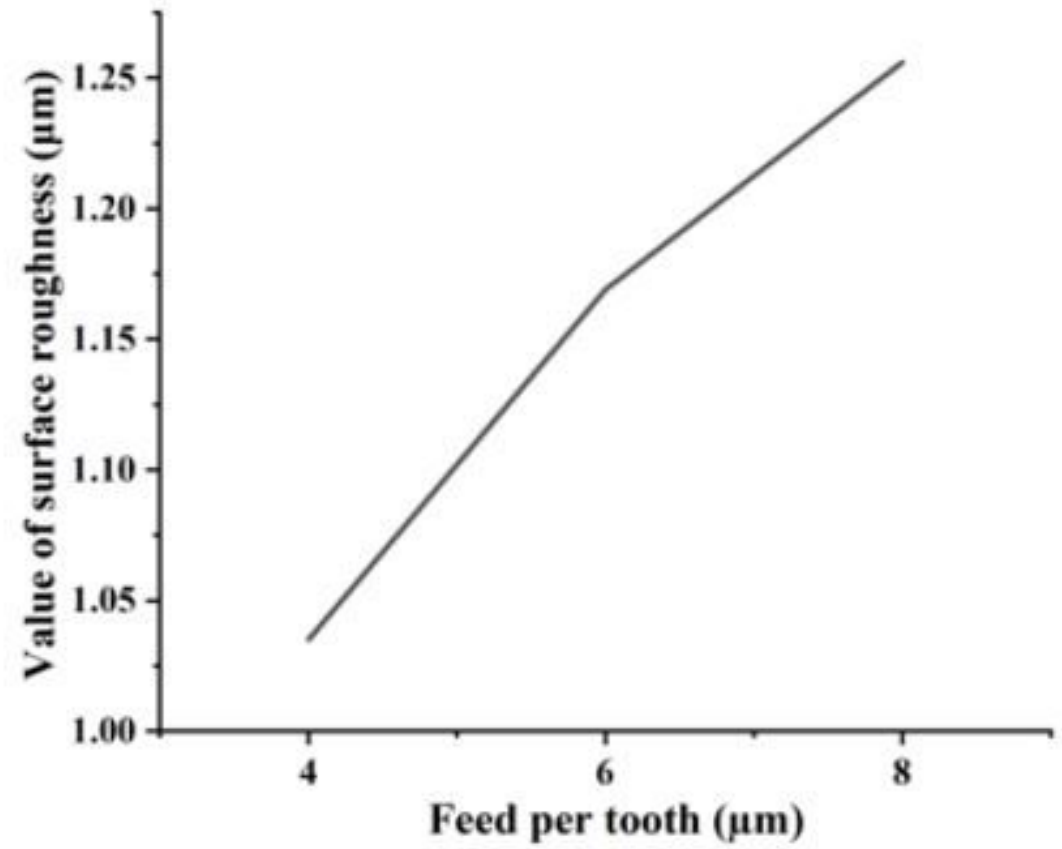

Figure 15

Surface roughness variation trend 

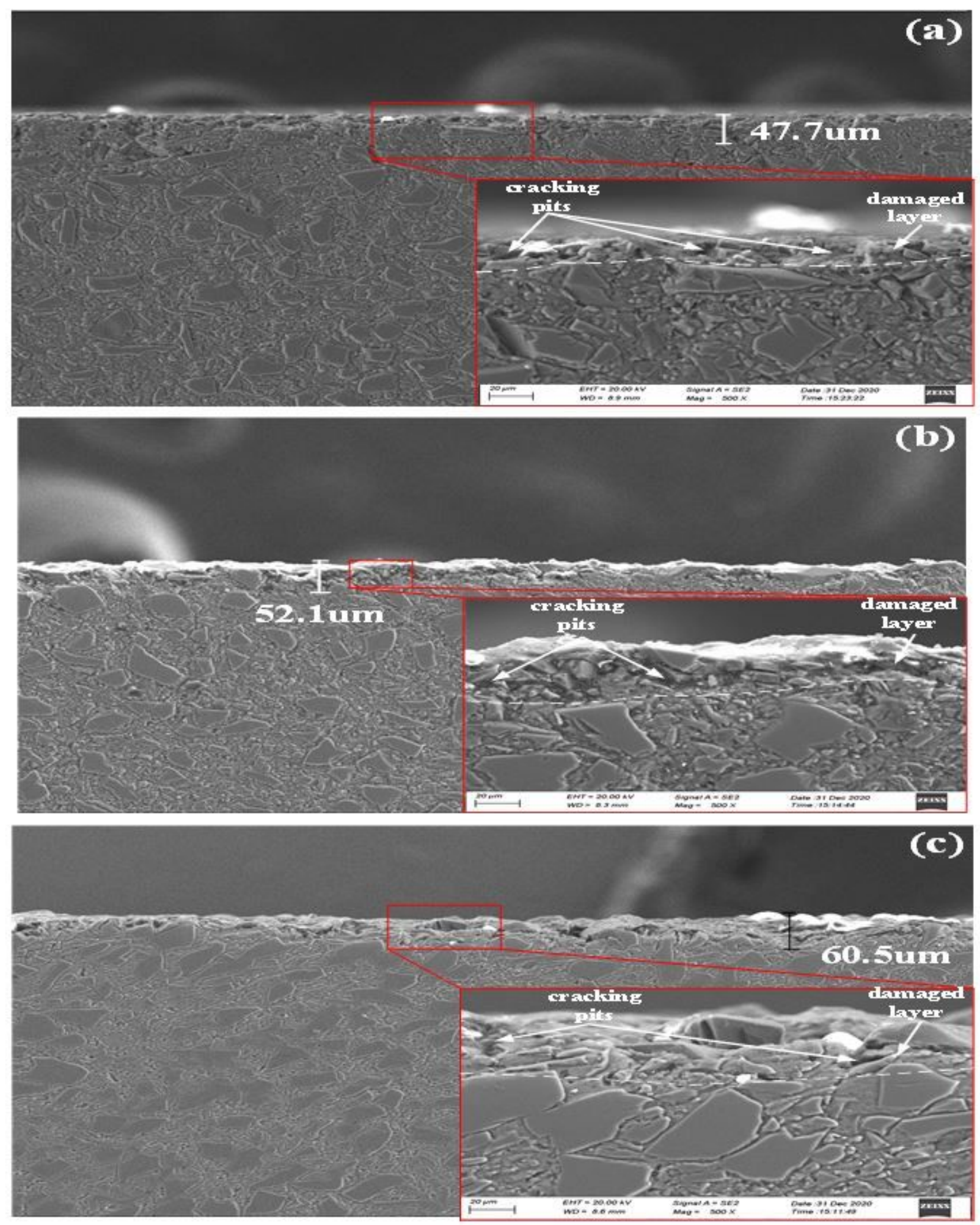

\section{Figure 16}

Detection of subsurface damage of composite materials (a) $\mathrm{N}=18000 \mathrm{r} / \mathrm{min}, \mathrm{Vf}=0.072 \mathrm{~m} / \mathrm{min}$, ap $=65 \mu \mathrm{m}$, $(f z=4 \mu \mathrm{m} / \mathrm{z}) ;(\mathrm{b}) \mathrm{N}=18000 \mathrm{r} / \mathrm{min}, \mathrm{Vf}=0.108 \mathrm{~m} / \mathrm{min}, \mathrm{ap}=65 \mu \mathrm{m},(\mathrm{fz}=6 \mu \mathrm{m} / \mathrm{z}) ;(\mathrm{c}) \mathrm{N}=18000 \mathrm{r} / \mathrm{min}, \mathrm{Vf}=0.144$ $\mathrm{m} / \mathrm{min}, \mathrm{ap}=65 \mu \mathrm{m},(\mathrm{fz}=8 \mu \mathrm{m} / \mathrm{z})$ 


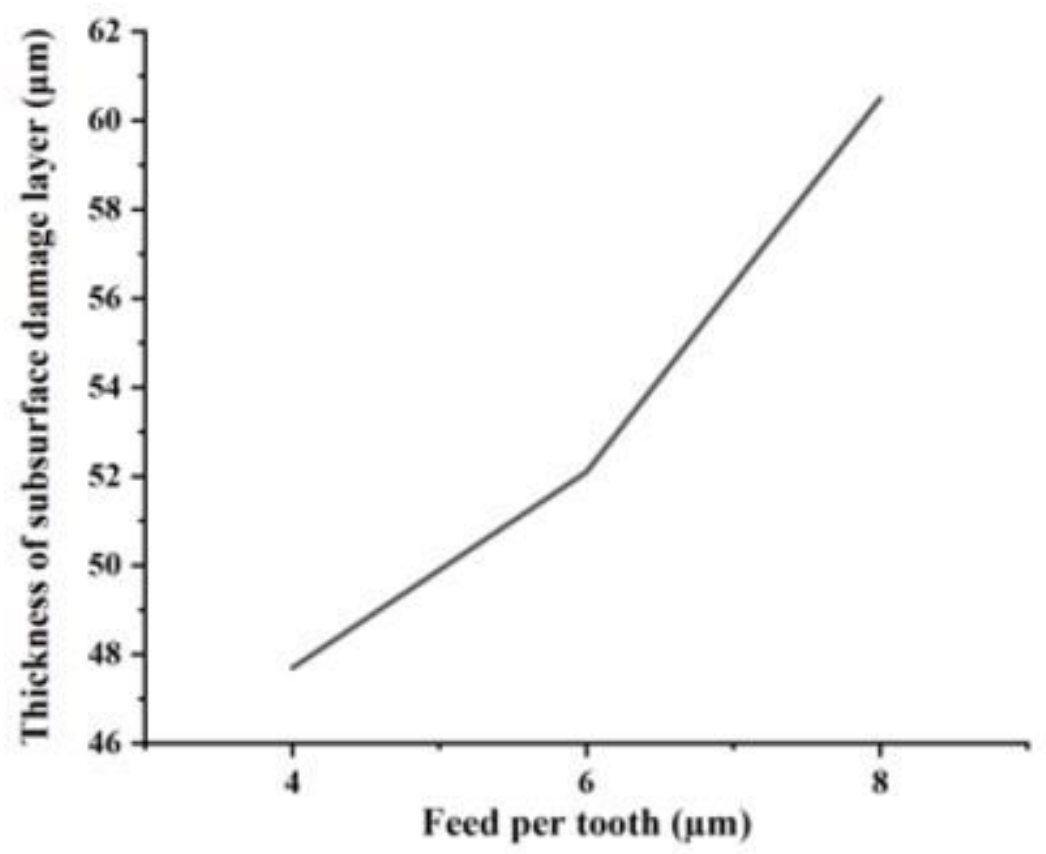

Figure 17

Thickness variation trend of subsurface damage layer 